ISSN: $1130-3743$

\title{
ESCUELA, PROFESORADO Y EDUCACIÓN MORAL
}

\author{
School, teachers and moral education
}

\section{École, professorat et éducation morale}

Miquel Martínez Martín, Josep María Puig Rovira y Jaume Trilla Bernet ${ }^{1}$

Universitat de Barcelona. Facultat de Pedagogia. Departament de Teoria $i$

Història de l'Educació. Passeig de la Vall d'Hebró, 171. 08035 Barcelona.

Correo-e: miquelmartinez@ub.edu, joseppuig@ub.edu, jtrilla@ub.edu

Fecha de recepción: diciembre de 2003

Fecha de aceptación definitiva: marzo de 2004

BIBLID [(1130-3743) 15, 2003, 57-94]

RESUMEN

La educación moral y cívica es, en cualquier circunstancia, uno de los principales empeños formativos de los educadores. En nuestro país, la reflexión y la práctica pedagógica en torno a la educación moral y cívica sufrió una brusca aceleración durante los años que van de la segunda mitad de los ochenta a la primera de los noventa. Nuestra intención en este artículo es considerar, mirando hacia el futuro, una serie de temas que fueron y son relevantes. Para alcanzar este objetivo, nos ha parecido oportuno dividir el escrito en cuatro partes destinadas a tratar temas distintos y complementarios. La primera servirá para analizar el contexto y las sucesivas propuestas legales relacionadas con la educación moral y cívica; en la segunda se presentará un modelo que distingue diferentes vías de formación y que nos servirá para adelantar algunas propuestas concretas de acción; en la tercera parte se debatirá

1. Las ideas contenidas en este trabajo son fruto de una labor de conjunto en la que, además de los autores del artículo, han participado las profesoras María Rosa Buxarrais, Xus Martín y Montserrat Payà. 
nuevamente el tema de la formación religiosa y de su relación con la educación en valores y, finalmente, se cerrará el escrito con una aproximación a las necesidades de formación que ha generado la educación moral y cívica.

Palabras clave: educación moral, escuela, formación del profesorado, educación y valores, laicismo.

\section{SUMMARY}

Moral and civic education is, under any circumstance, one of the most significant educational undertakings assumed by educators. In Spain, educational reflection and practice in respect to moral and civic education underwent a sudden acceleration in the years from the late eighties to the early nineties. Our aim in this article is to consider a number of subjects that were relevant then and remain so today, looking forward into the future. To achieve this aim we thought it best to divide the text into four parts, each dealing with distinct but complementary themes. The first will serve to analyse the context and successive legal proposals with relation to moral and civic education; in the second we will offer a model which distinguishes different lines of training and which we will use to present a number of specific action proposals; the third part offers us the opportunity to revisit the debate on the subject of religious education and its relationship to values education; and finally the text will close with a review of the training requirements produced by moral and civic education.

Key words: moral education, school, teacher's training, values education, secularism.

\section{SOMMAIRE}

L'éducation morale et civique est, en tout état de cause, l'un des principaux buts de formation des éducateurs. Dans notre pays, la réflexion et la pratique pédagogique autour de l'éducation morale et civique a souffert une brusque accélération entre la deuxième moitié des années quatre vingt et la première moitié des années quatre vingt dix. Dans cet article, notre intention est de considérer une série de thèmes qui ont été et sont d'intérêt tout en regardant vers le futur. Pour atteindre cet objectif, il nous a paru opportun de diviser cet écrit en quatre parties destinées à traiter des thèmes différents et complémentaires. La première servira à analyser le contexte et les propositions légales successives en relation avec l'éducation morale et civique; dans la deuxième, sera présenté un modèle que distingue différentes voies de formation et qui nous servira à introduire quelques propositions concrètes d'action; dans la troisième, nous débattrons, à nouveau, le thème de la formation religieuse et de sa 
MIQUEL MARTÍNEZ MARTÍN, JOSEP MARÍA PUIG ROVIRA Y JAUME TRILLA BERNET ESCUELA, PROFESORADO Y EDUCACIÓN MORAL

relation avec l'éducation de valeurs; et finalement nous terminerons ce travail avec une approche aux nécessités de formation qu'a généré l'éducation morale et civique.

Mots clef: éducation morale, école, formation du professorat, éducation et valeurs, laïcisme.

Casi en silencio o bien de forma declarada, la educación moral y cívica es en cualquier circunstancia uno de los principales empeños formativos de los educadores. Sin embargo, también es cierto que en ocasiones la reflexión y la práctica pedagógica sufren una brusca aceleración. En nuestro país, la educación moral y cívica vivió un giro de esta naturaleza durante los años que van de la segunda mitad de los ochenta a la primera de los noventa. El desarrollo fue intenso y ha sido convenientemente analizado ${ }^{2}$. Nuestra intención en este artículo no es volver sobre esta cuestión, sino considerar mirando hacia el futuro una serie de temas que fueron y son relevantes. Considerarlos a veces con la intención de repetir cosas dichas que todavía nos parecen válidas y otras veces intentando llevar las propuestas un poco más lejos de donde nos habían quedado. Para alcanzar este objetivo, nos ha parecido oportuno dividir el escrito en cuatro partes destinadas a tratar temas distintos y complementarios. La primera servirá para analizar el contexto y las sucesivas propuestas legales relacionadas con la educación moral y cívica; en la segunda se presentará un modelo que distingue diferentes vías de formación y que nos servirá para adelantar algunas propuestas concretas de acción; en la tercera parte se debatirá nuevamente el tema de la formación religiosa y de su relación con la educación en valores y, finalmente, se cerrará el escrito con una aproximación a las necesidades de formación que ha generado la educación moral y cívica.

\section{LA EDUCACIÓN MORAL EN EL CONTEXTO DEL SISTEMA EDUCATIVO ESPAÑOL}

\subsection{Contexto, educación y educación moral}

Las propuestas pedagógicas se generan, adquieren sentido y significado y se concretan en contextos. Las propuestas de educación cívica lo hacen de forma intensa y las propuestas de educación moral están influidas de forma notable por el mundo de los valores propio de cada contexto sociocultural y por los diferentes niveles que desde una perspectiva constructivista ${ }^{3}$ y contextualista ${ }^{4}$ caracterizan el sistema de vida y aprendizaje en el que crecemos y nos educamos. Por ello,

2. EscÁmez, J. (2003) Los valores y la educación en España (1975-2001), en SITE. Teoría de la Educación, ayer y boy. Murcia, 205-237.

3. Rogoff, B. (1993) Aprendices del pensamiento. Barcelona, Paidós.

4. Bronfenbrenner, U. (1987) La ecología del desarrollo bumano. Barcelona, Paidós. 
pensamos que es conveniente iniciar nuestra colaboración con un conjunto de consideraciones en relación al exosistema y al macrosistema que han conformado la educación moral en el sistema educativo español a lo largo de las últimas décadas.

Entendemos que de esta forma resultará más fácil desarrollar los apartados siguientes en los que analizaremos diferentes espacios y escenarios de educación moral y propondremos orientaciones en relación con la formación del profesorado y de los profesionales de la educación en este ámbito. Recordar la historia más reciente y situarnos en el umbral de lo que puede ser la nueva realidad educativa derivada del actual contexto legal y político regulado por la LOCE puede ser una buena manera para comprender que las propuestas de educación moral no son sólo propuestas de carácter estrictamente pedagógico, sino que también son propuestas políticas y sociales que reclaman no sólo formación de profesionales, elaboración de materiales u orientaciones curriculares que garanticen el trabajo pedagógico y sistemático con relación al desarrollo moral y la educación en valores en el aula. Son propuestas que reclaman una forma de pensar la escuela, una nueva mirada en el profesorado y un contexto social, político y también legal en materia educativa preocupado por la creación de capital humano, capital social y ciudadanía activa capaz de profundizar en valores y estilos de vida democráticos y en los niveles de inclusión social tanto en el ámbito local como global.

Sabemos que la educación, en cualquiera de sus facetas y niveles, está siempre condicionada por la estructura sociopolítica que la cobija. Es así que el aparato escolar en general se configura en cada país en relación a factores tales como su nivel de desarrollo económico, la forma de su sistema político, los partidos o mayorías que en cada momento gobiernan y legislan, los poderes fácticos de ciertos grupos de presión como, por ejemplo, las iglesias o confesiones religiosas. Sin embargo, aquí queremos insistir en que, si bien es cierto que todos estos factores actúan sobre el conjunto global de la educación y de la escuela, es sobre el ámbito específico de la educación moral, y también de la educación política, cívica y religiosa, donde las correspondencias se suelen manifestar de una forma más obvia y directa.

\subsection{La educación moral en la bistoria del sistema educativo español del siglo $\mathrm{XX}$ basta la promulgación de la Constitución}

El lugar de la educación moral en la historia del sistema educativo español del pasado siglo ha sido objeto de enconados enfrentamientos, tanto en el terreno de las ideas como en el de las prácticas. Sin duda, este hecho no ha sido privativo del caso español, pero el particular contexto político y social en el que se ha desarrollado la educación en España ha hecho que el problema de la educación moral adquiriera una peculiaridad especial y distintiva respecto a otros países de nuestro entorno socioeconómico.

De forma sucinta y simplificando, podemos decir que, hasta el advenimiento de la democracia, la historia de la educación moral en la escuela de la España del 
siglo pasado debe explicarse a partir de, entre otras, las realidades contextuales siguientes 5 .

En primer lugar, la predominancia de sistemas políticos totalitarios que impondrían modelos educativos de carácter fuertemente adoctrinador. Con ello, los objetivos de la educación moral generalizada en la escuela se reducían a la voluntad de inculcar unilateralmente los valores y las normas propias de las ideologías políticas y religiosas en el poder ${ }^{6}$.

En segundo lugar, la potente implantación de la Iglesia católica como poder fáctico real, tanto por lo que se refiere a su influencia en las estructuras políticas como a su presencia en la sociedad civil, decantó de forma muy excluyente los contenidos de la educación moral hacia los valores propios del catolicismo, leídos a menudo en versiones reaccionarias.

En tercer lugar, durante los periodos de funcionamiento político democrático, la escasa duración de los mismos y la crispación de los enfrentamientos entre las distintas posiciones sociales, políticas y religiosas presentes en el panorama español dificultaron el establecimiento de unas coordenadas favorables para la generalización de un planteamiento realmente pluralista, abierto, tolerante y no doctrinario de la educación moral. Así, la lucha entre posicionamientos confesionales muy cerrados y un laicismo antirreligioso muy beligerante, sólo atenuada por las posiciones de "neutralidad" o de laicismo respetuoso como las de la Institución Libre de Enseñanza, marcó muy considerablemente la educación moral en la escuela durante, por ejemplo, el corto periodo de la II República Española.

Todo ello motivó que la controversia sobre el lugar, los contenidos y los métodos de la educación moral en la escuela española estuviera constantemente penetrada por connotaciones e intereses sectarios que, a menudo, distorsionaban lo que debería ser una polémica pacífica, racional y distendida de carácter ético y pedagógico. Así, por ejemplo, durante la dictadura franquista (1939-1975) la identificación de la educación moral con la educación religiosa, exclusivamente católica y, a menudo, con una orientación bastante retrógrada, motivó, hasta hace todavía pocos años, un descrédito considerable de la primera entre los sectores más progresistas

5. Las fuentes bibliográficas sobre la historia de la educación en la España contemporánea son muy numerosas. Nos limitaremos, por ello, a indicar una obra general muy apropiada para contextualizar el periodo histórico que comentamos: DE Puelles, M. (1980) Educación e ideología en la España contemporánea. Barcelona, Labor.

6. Naturalmente, los sistemas educativos, incluso bajo regímenes totalitarios, nunca son totalmente monolíticos y uniformes. En ellos siempre hay fisuras y espacios para la resistencia y la disidencia. Estos espacios también han existido respecto a la educación moral en la escuela española durante las dictaduras. Espacios que eran aprovechados por maestros y escuelas que se resistían - por omisión o beligerantemente - a la tarea de inculcar los valores que el sistema imponía. Por otro lado, y por lo que se refiere particularmente a los últimos periodos del régimen franquista, la ideología real (difusa y, a menudo, subterránea, pero efectivamente extendida) no se correspondía ya con la ideología oficial del sistema político. Éste era disfuncional con la realidad económica, social y cultural, y, por tanto, los valores efectivos eran distintos de los que se pretendía que la escuela inculcase. 
e innovadores de la teoría de la educación y la práctica escolar. La educación moral era percibida por tales sectores como algo casi privativo del ámbito religioso y de las corrientes pedagógicas más emparentadas con las ideologías que iban legitimando el Estado franquista. Incluso la propia expresión "educación moral" aparecía contaminada por las adherencias religiosas y políticas que fue acumulando durante los casi cuarenta años de régimen dictatorial.

\subsection{La Constitución y su incidencia en la remodelación del sistema educativo español}

La transición política que se inicia con la muerte del general Franco en 1975 y la promulgación en 1978 de la actual Constitución pondrían las bases políticas y jurídicas para remodelar el sistema educativo español en orden a adaptarlo a la nueva situación democrática. Antes de entrar, sin embargo, en la descripción de los contenidos de la citada Constitución que están directamente relacionados con el tema que nos ocupa, conviene referirnos muy brevemente a algún aspecto del proceso mediante el cual fue elaborada y aprobada. Ello ayudará a entender algunas de las virtualidades y problemas del texto constitucional en lo que se refiere a la educación.

La Constitución española de 1978 fue fruto del consenso entre la mayoría de las fuerzas parlamentarias del momento. La elaboración de un texto constitucional que fuera asumible por la mayor parte posible de las fuerzas políticas del país fue, sin duda, un acierto. Ello obligó, naturalmente, a que todos los partidos que consensuaron el texto hicieran concesiones parciales, de modo que la Constitución resultante, aunque no fuera enteramente del gusto de nadie, pudiera ser aceptable por todos. Pero esta voluntad de consenso dio lugar también a la introducción en algunos artículos de un notable grado de ambigüedad con la consiguiente posibilidad de interpretaciones no sólo distintas sino incluso antagónicas. Precisamente, una de las partes del texto constitucional en las que resultó más difícil llegar al consenso fue la destinada a la cuestión educativa ${ }^{7}$. Como consecuencia de todo ello, los epígrafes constitucionales sobre educación han estado entre los que han generado mayores controversias en los desarrollos legislativos subsiguientes ${ }^{8}$.

Con posterioridad a la Constitución y hasta la fecha, se han aprobado en España cuatro leyes educativas fundamentales relacionadas con nuestro tema, una de ellas con posterioridad al año 2000. En primer lugar, la Ley Orgánica del Estatuto de Centros Escolares (LOECE) promulgada en 1980 a partir de la mayoría parlamentaria que en aquel momento ostentaba el partido Unión de Centro Democrático. Esta ley fue derogada y sustituida por la Ley Orgánica del Derecho a

7. De la copiosa bibliografía existente sobre la Constitución española y la educación nos limitaremos a citar el extenso y minucioso análisis valorativo de AGLADO, R. (1988) Principios Constituciona les del Sistema Educativo Español. Madrid, Ministerio de Educación y Ciencia.

8. Ver EmBid IRLjo, A. (1985) La jurisprudencia del Tribunal Constitucional sobre enseñanza, Revista Española de Derecho Administrativo, 15. 
la Educación (LODE), aprobada en 1985 bajo el gobierno del Partido Socialista Obrero Español. Ambas leyes fueron recurridas en su momento al Tribunal Constitucional, pero tanto la una como la otra pueden ser consideradas coherentes con el articulado de la Constitución. El hecho de que de un mismo texto constitucional puedan desprenderse dos ordenamientos jurídicos tan dispares es, pues, un claro indicador del antes aludido carácter abierto, en una valoración positiva, o ambiguo, si se prefiere una valoración menos positiva, de la actual Constitución española. Una tercera ley fundamental fue la Ley de Ordenación General del Sistema Educativo (LOGSE). Esta ley, complementaria de la LODE, tiene una incidencia directa sobre los aspectos curriculares y de contenidos. La cuarta ley es la Ley de la Calidad de la Educación (LOCE) aprobada ya en el siglo XXI y a la que nos referiremos en el siguiente apartado.

El artículo 27 de la Constitución es el que está íntegramente consagrado a la educación. Seguidamente, expondremos los contenidos constitucionales que, de una forma u otra, tienen que ver con la educación moral. El artículo 27.1, después de afirmar el derecho de todos a la educación, reconoce como principio del sistema educativo "la libertad de enseñanza". La amplitud y la ambigüedad de esta formulación genérica ha sido objeto de múltiples controversias interpretativas?. Así, por ejemplo, la "libertad de enseñanza" ha sido entendida como la facultad de difundir libremente los conocimientos y las propias opiniones, la cual estaría relacionada con otras formulaciones explícitas en la Constitución como la «libertad de expresión" y la "libertad de cátedra" ". También la "libertad de enseñanza" se ha entendido como la facultad de crear centros docentes, derecho explícitamente reconocido en el artículo 27.6 y que supone en la práctica la negación de un posible monopolio estatal en materia educativa. De igual forma la ulibertad de enseñanza" se ha podido interpretar como el reconocimiento del derecho de los padres a elegir el centro docente de sus hijos, el cual puede relacionarse, aunque no identificarse, con el artículo 27.3 que dice textualmente: "Los poderes públicos garantizan el derecho que asiste a los padres para que sus hijos reciban la formación religiosa y moral que esté de acuerdo con sus propias convicciones". Finalmente, el precepto constitucional de la "libertad de enseñanza" se ha extendido igualmente a los propios educandos. En el preámbulo de la LODE, después de recoger bajo un concepto muy comprensivo las anteriores interpretaciones, se afirma que la libertad de enseñanza abarca también a los educandos, "respecto de los cuales la protección de la libertad de conciencia constituye un principio irrenunciable que no puede supeditarse a ningún otron.

9. Ver Aguado: op. cit., 77 y ss. También EmBid IRujo, A. (1983) Las libertades de la enseñanza. Madrid, Tecnos.

10. "Se reconocen y protegen los derechos: a) A expresar y difundir libremente los pensamientos ideas y opiniones mediante la palabra, el escrito o cualquier otro medio de reproducción [...] c) $\wedge$ la libertad de cátedra. [...]" (Const., art. 20.1). "Estas libertades tienen su límite en [...] la protección de la juventud y de la infancia" (Const., art. 20.4). 
Para completar este panorama es importante mencionar también el artículo 27.2 que establece que ala educación tendrá por objeto el pleno desarrollo de la personalidad humana en el respeto a los principios democráticos de convivencia y a los derechos y libertades fundamentales". Y, para enmarcar las anteriores formulaciones, debe tenerse también en consideración el reconocimiento de la "libertad ideológica, religiosa y de culto de los individuos y comunidades" de acuerdo con el artículo 16.1 y el carácter aconfesional del Estado español de acuerdo con el artículo $16.3^{11}$.

La combinación de todos estos preceptos constitucionales $-\mathrm{y}$ de los que a ellos se refieren en las leyes posteriores - ha generado numerosas polémicas directa o indirectamente relacionadas con el sentido y el lugar de la educación moral en el sistema educativo español. Como hemos dicho, el texto constitucional reconoce explícitamente el derecho de los padres a que los poderes públicos garanticen que sus hijos reciban la formación religiosa y moral de acuerdo con las convicciones de los primeros. Ello puede leerse de varias formas distintas. En primer lugar, se plantea el problema de si las escuelas deben reservar espacios específicos para la formación moral y religiosa, de acuerdo con las convicciones de los padres. Dicho de otro modo, si la enseñanza o formación religiosa debe ser o no una asignatura más del plan de estudios.

Pero el reconocimiento del derecho de los padres sobre la orientación de la formación moral y religiosa de sus hijos puede plantear otras cuestiones. Si se entiende que este tipo de formación también se adquiere en la escuela de una forma más difusa que a través de una asignatura especial, es decir, atravesando otras materias curriculares y, sobre todo, por medio de las vivencias, del clima general y de las actitudes personales de los maestros, la cuestión cobra otras perspectivas igualmente controvertidas. Por ejemplo, con ello se relaciona la contraposición entre dos modelos de sistema educativo: un modelo que contemple una pluralidad de escuelas diferenciadas entre sí por la especificidad ideológica de cada una de ellas o bien un modelo que introduzca el pluralismo ideológico en cada escuela. La realidad de como se ha venido configurando el sistema educativo español, en cierto modo, combina ambos modelos. De hecho, la LODE contempla la posibilidad de la existencia de escuelas privadas con un ideario o, literalmente, con un "carácter propio" ${ }^{12} \mathrm{y}$, a la vez, establece que los centros públicos deberán garantizar la neutralidad ideológica ${ }^{13}$.

11. "Ninguna confesión tendrá carácter estatal. Los poderes públicos tendrán en cuenta las creencias religiosas de la sociedad española y mantendrán las consiguientes relaciones de cooperación con la Iglesia católica y las demás confesiones" (Const., art. 16.3).

12. El artículo 22.1 de la LODE. Dice: “En el marco de la Constitución y con respecto de los derechos garantizados en el Título Preliminar de esta ley a profesores, padres y alumnos, los titulares de los centros privados tendrán derecho a establecer el carácter propio de los mismos".

13. El artículo 18.1 de la LODE. Dice: "Todos los centros públicos desarrollarán sus actividades con sujeción a los principios constitucionales, garantía de neutralidad ideológica y respeto a las opciones religiosas y morales que hace referencia el artículo 27.3 de la Constitución". 
La coexistencia de ambos tipos de centros, sin embargo, no ha agotado la discusión. Así, por ejemplo, cabe plantear cuáles serían los límites del "carácter propio" de los centros privados en lo que se refiere a la transmisión de valores morales. En teoría estos límites se encuentran definidos en los preceptos que garantizan el respeto a los derechos y libertades fundamentales, el ejercicio de la tolerancia y la convivencia, la libertad de conciencia y la dignidad de los alumnos, etc. ${ }^{14}$. Pero en la práctica, como es de suponer, no siempre resulta fácilmente distinguible dónde termina la voluntad de transmitir honestamente los valores morales o religiosos o políticos contenidos en el "carácter propio" del centro y dónde empieza la intención de adoctrinar, manipular o hacer proselitismo, procedimientos incompatibles con una formación para la tolerancia, el respeto a la dignidad y a la libertad de conciencia del alumno.

En resumen, la Constitución española no constituye un marco en el que sea fácil dirimir unívocamente muchas de las controversias que se generan en torno a la educación moral en el sistema educativo. Ello no debe suponer, sin embargo, una valoración negativa de la misma. Independientemente de las dosis de ambigüedad intencionalmente introducidas en el texto en función del procedimiento consensual antes explicado, el propio carácter amplio y genérico de una constitución lógicamente imposibilita la incorporación de criterios capaces de determinar directa y explícitamente cuestiones concretas como las que nos ocupan. Leyes posteriores y jurisprudencia del Tribunal Constitucional han ido perfilando ciertos aspectos directa o indirectamente relacionados con la educación moral en la escuela española. Todo ello se ha dado en un contexto de profundas y, en ocasiones, duras controversias entre partidos políticos, grupos de presión, estamentos educativos, etc. Lo cual, por otro lado, es consustancial con un Estado democrático. La educación moral institucionalizada en el sistema educativo, al menos tal y como nosotros la entendemos, exige libertad de conciencia y de expresión, tolerancia y aceptación del pluralismo ideológico, exige, en definitiva, un marco democrático. Por ello, salvo en algunos momentos históricos bastante excepcionales y de corta duración, no es hasta el advenimiento del actual Estado democrático que en España se ha podido empezar a plantear y a diseñar correctamente el espacio de la educación moral en la escuela.

14. "La actividad educativa, orientada por los principios y declaraciones de la Constitución, tendrá en los centros docentes a que se refiere la presente ley, los siguientes fines: a) El pleno desarrollo de la personalidad del alumno, b) La formación en el respeto y las libertades fundamentales y en el ejercicio de la tolerancia y de la libertad dentro de los principios democráticos de convivencia. [...], f) La preparación para participar activamente en la vida social y cultural, g) La formación para la paz, la cooperación y la solidaridad entre los pueblos" (LODE, art. $2^{\circ}$ ). "Se reconoce a los alumnos los siguientes derechos básicos: [...], c) Derecho a que se respete su libertad de conciencia, así como sus convicciones religiosas y morales, de acuerdo con la Constitución, d) Derecho a que se respete su integridad y dignidad personales» (LODE, art. 6). 
En 1990 se aprueba la Ley de Ordenación General del Sistema Educativo (LOGSE). Esta ley, como hemos dicho, establece los distintos niveles no universitarios del sistema educativo y tiene, pues, una incidencia directa sobre los aspectos curriculares y de contenidos. Es, pues, de una importancia fundamental con relación al lugar que ha de tener la educación moral o ética en nuestro sistema educativo formal. Hay que decir que a la formación moral, a menudo bajo otras formulaciones, parece que se le asigne una importancia muy notable cuando se anuncian finalidades y objetivos o se explicitan intenciones. Sin embargo, la propia ley y los desarrollos que surgieron de ella propiciaron unos considerables márgenes de indefinición y de ambigüedad en el momento de situar concretamente los espacios curriculares y los momentos en la actividad escolar en los que esta formación moral deberá ubicarse tal y como señalábamos en un trabajo anterior ${ }^{15}$.

Uno de ellos fue el del carácter de materia transversal que finalmente tuvo la formación moral en el currículum. En principio y teóricamente, esta transversalidad puede ser justificable y positiva en diversos aspectos y desde algunas perspectivas. Ciertamente, la educación moral conecta directamente con otras muchas áreas curriculares y muchos de los temas de la misma pueden quedar debidamente contextualizados en tales áreas. Por otro lado, también es acertado que sean todos los profesores quienes compartan y se responsabilicen de acometer la formación en esta dimensión esencial de la educación integral. Sin embargo, el peligro real es también obvio: cuando algo es responsabilidad de todos, a menudo termina por no ser responsabilidad de nadie. La posibilidad de que la transversalidad pudiera diluir y terminar por minimizar la presencia efectiva de la educación moral en la escuela ha sido parcialmente cierta en parte por el propio carácter transversal y, sobre todo, por la falta de una formación acorde en el profesorado. En este sentido, la no adecuación de los planes de formación inicial del profesorado, responsabilidad que en buena parte corresponde a las universidades, y la confianza en que la falta de preparación de los que ya ejercían se subsanara a través de acciones de formación permanente no estuvieron acompañadas por los recursos suficientes ni por una complicidad eficaz de la administración educativa.

Otro de los problemas que la LOGSE suscitó en conexión directa o indirecta con el tema de la educación moral fue el del lugar de la enseñanza religiosa en la escuela. Aunque a buen seguro no es la más relevante, sí que es probablemente la cuestión que más debate público produjo la antedicha ley.

15. Concretamente, en la ponencia elaborada por M. R. Blxarrais, M. Martínez, J. M. Puig y J. TriLLA sobre Moral Education in Spain: A Report from the group for Research on Moral Education of the University of Barcelona, presentada al Symposium Internacional, Values, Rights, and responsabilities in the International Community: Moral Education for the Millenium, celebrado en la Universidad de Notre Dame, Indiana, LSA, en noviembre de 1990. Parte de la anterior panorámica sobre la educación moral en el sistema educativo español está también basada en el trabajo de BuXARRAIS, M. R.; MARTíNeZ, M.; Puig, J. M. y TRILlA, J. (1994) Moral Education in the Spanish Educational System, The Journal of Moral Education, 23, 39-59. 


\subsection{La ley de Calidad de la Educación (LOCE)}

Aprobada la ley el 13 de enero de 2003 y a la luz de algunos de los reglamentos y disposiciones que la desarrollan, no parece que estemos ante una ley que vaya a resolver de forma satisfactoria las cuestiones pendientes en orden a consolidar el modelo de educación moral que proponemos. Más bien al contrario, parece que estamos ante tiempos adversos para la educación moral y para la implantación de un modelo de educación cívica-moral orientado a la formación de una ciudadanía activa, crítica e interesada en incrementar los niveles de inclusión social.

No se trata sólo de una cuestión curricular o de estar o no de acuerdo con lo que los autores de la ley afirman en el preámbulo y declaración de principios que la acompaña. Se trata del modelo de escuela y de aprendizaje que la misma plantea. Un modelo que, lejos de ser un modelo inclusivo y generador de convivencia en contextos heterogéneos, prima el éxito individual, promueve agrupaciones no flexibles de alumnos, abre la puerta a la especialización de escuelas en función del rendimiento en los aprendizajes de sus alumnos, no genera la necesidad del trabajo del profesorado en equipo, ni por áreas ni ciclos, y no fomenta, cuando no impide, situaciones que estimulen la participación ${ }^{16}$.

Así, por ejemplo, en lugar de corregir los evidentes defectos y errores presentes en la dinámica y sistema de funcionamiento de los consejos escolares, se opta por reducir las competencias de los mismos y prescindir de hecho de los procesos de participación que puedan incidir en el gobierno y gestión de los centros.

De igual forma, faltan en el actual ordenamiento legal objetivos relativos a algunos contenidos de aprendizaje y criterios que aseguren el desarrollo de algunas competencias básicas relacionadas con la educación moral, con los dominios del aprender a ser y del aprender a convivir juntos.

Parece como si lo único que mereciera la pena es la instrucción y la incorporación eficiente al mundo laboral o del estudio. La organización de los espacios de aprendizaje en función del rendimiento por asignaturas puede dificultar no sólo el logro de competencias generales sino incluso el logro de aquellas competencias específicas que obviamente no pueden circunscribirse ni están vinculadas a asignaturas sino a las diferentes áreas del saber y del saber hacer. En este sentido, la desaparición del ciclo y del área como espacios de convivencia y aprendizaje, por el curso y la asignatura, no es precisamente un avance.

En el apartado anterior nos lamentábamos de los defectos que la LOGSE presentaba en relación con la educación en valores y la educación moral y mencionábamos el tratamiento de lo religioso en la escuela como la cuestión que quizás más debate generó. Pues bien, la LOCE aborda la cuestión como si de otro tiempo se tratara. La manera como la ley aborda una cuestión a la vez tan relevante como

16. Martínez, M.; Blyarrais, M. R.; Martín, X.; Payà, M.; Plig, J. M. y Trilla, J. (2003) Respuestas a seis preguntas sobre ciudadanía y educación para la ciudadanía en España, Revista de Educación, número extraordinario 2003, 407-424. 
controvertida como es el tratamiento de lo religioso en la escuela en una sociedad plural y democrática está generando crispación, sentimientos antirreligiosos y dificultades para abordar el tema desde la perspectiva pedagógica que requiere.

En todo caso, conviene ser optimistas y confiar en que los momentos difíciles pueden ser favorables si se abordan como oportunidades. Apostamos por incidir sobre los equipos de profesorado a través de acciones formativas de sensibilización y capacitación, generar un clima de debate en relación con las cuestiones pedagógico-morales en todos los foros posibles y contribuir, en la medida de nuestras posibilidades, a profundizar en nuestras propuestas tanto teóricas como prácticas.

\section{LOS ESPACIOS DE LA EDUCACIÓN MORAL EN LA ESCUELA}

La escuela, a pesar de ciertas apariencias, constituye un medio educativo muy polivalente y complejo. Y ello, por supuesto, se refiere también a la educación moral que esta institución es capaz de producir. Los valores (y, en ocasiones, también ciertos contravalores) circulan y se instalan en la escuela a través de múltiples canales y lugares. Los argumentan los profesores y ellos mismos, estos valores que verbalizan $\mathrm{o}$, incluso, contradictoriamente sus opuestos, los ejemplifican con su manera de actuar; los valores también se aprenden en actividades diseñadas expresamente para ello (discutiendo hipotéticos dilemas morales, por ejemplo) y se viven directamente dialogando sobre un conflicto moral y actual en la asamblea de clase; están presentes explícita o enmascaradamente en los libros de texto, en las valoraciones e interpretaciones en clase de sociales, de literatura, o en la moraleja de un dictado; en el procedimiento para distribuir los lugares en la clase y en la participación en la fiesta del carnaval del barrio; hay valores morales en la conversación informal de la maestra con un niño a la entrada de la clase y en cómo los alumnos organizan un juego durante el recreo. Es, por esa multitud y diversidad de momentos, actividades, encuentros, vivencias, recursos y métodos de educación moral en la escuela, que para tratar sobre ella con un mínimo de sentido es necesario ordenar este caos aparente. El sistema de ordenación que proponemos y que vamos a desarrollar a continuación consta de cuatro espacios que denominaremos así: el de las relaciones interpersonales, el de las tareas curriculares, el de la cultura escolar y el comunitario.

\subsection{El espacio de las relaciones interpersonales}

El primer nivel del modelo de formación cívico-moral que nos proponemos presentar centra su atención en los vínculos interpersonales que se establecen entre los educadores y sus alumnos. Sin embargo, las relaciones interpersonales no constituyen un espacio con fronteras nítidas que puedan delimitarse en relación a otros momentos con semejante relevancia formativa. Muy al contrario, aparecen y forman parte de cualquier momento educativo. Las relaciones interpersonales no son 
un tipo de actividad entre otras, sino que surgen en el interior de cualquier situación educativa: tienen algo de transversal y omnipresente. Ahí radica precisamente parte de su complejidad e importancia: no suelen llegar a programarse reflexivamente debido a que por lo general se presentan en forma de breves episodios - los encuentros-, aunque tales unidades aparecen y se desarrollan a lo largo de todas las demás experiencias educativas y acaban por dar forma a un vínculo educativo complejo. Pese a lo que llevamos dicho, en la actualidad hablar de relaciones interpersonales resulta algo muy impreciso. Es una expresión que se utiliza para referirse a formas muy distintas de entender el trato entre personas; a formas que pueden manifestar una naturaleza y unos objetivos muy dispares. Bajo una misma denominación se engloban realidades casi opuestas: las relaciones interpersonales pueden ser un medio para objetivar y sujetar a los alumnos, pero también pueden constituir un espacio de reconocimiento pleno del otro en tanto que ser humano singular.

A veces la educación convierte las relaciones interpersonales en un ejercicio de saber dirigido a objetivar a los educandos y en un ejercicio de poder pensado para disciplinarlos. Como tan certeramente ha explicado Foucault, la mirada no busca aquí el rostro de un ser humano que me interpela y espera mi aliento, sino que la mirada analiza, fija y al fin objetiva el modo de ser del otro. Y, por si fuera poco, la mirada vigila con atención que ningún acto sobrepase lo que establecen las normas: la mirada sujeta y disciplina ${ }^{17}$. Quizás sería mejor analizar menos a los alumnos y vincularnos mucho más a ellos a través de manifestaciones más explícitas de afecto. La educación también se ha visto envuelta en el "olvido del otro" que sufre nuestra civilización ${ }^{18}$. El otro se hiela en nuestras manos: se objetiva, instrumentaliza, cosifica y acaba por desaparecer como persona.

La relación educativa auténtica no está pensada para objetivar y disciplinar, sino para convertir al sujeto con el que se comparte una situación formativa en "alguien reconocido"; en alguien con quien se traban lazos morales en un doble sentido: de responsabilidad del adulto hacia el joven y de respeto del joven hacia el adulto. Pero veamos uno a uno los elementos que componen una relación educativa auténtica: 1) un encuentro, 2) un encuentro de acogida y reconocimiento y 3) un encuentro que genera cualidades morales de responsabilidad y respeto.

Que la educación supone interacción entre educadores y educandos es algo que resulta obvio. La cuestión es ver si esa interacción es sólo un mero contacto entre sujetos-objetivados que llevan a cabo un intercambio que no va más allá del previsto en el rol que desempeñan. O si, por el contrario la interacción es un verdadero encuentro entre individuos singulares ${ }^{19}$. Es decir, una relación cara-a-cara

17. Folcallt, M. (1976) Vigilar y castigar. México, Siglo xxI.

18. MĖLıCH, J. C. (1998) Totalitarismo y fecundidad. Barcelona, Anthropos.

19. Vamos a destacar dos autores que, aunque no son los únicos relevantes, se han planteado el tema del encuentro como clave en su pensamiento. Uno de ellos, Goffman, lo ha hecho desde posiciones sociológicas, y el otro, Buber, desde posturas filosóficas. Goffmax, E. (1970) El ritual de la 
entre dos sujetos que a través del rostro, el gesto y la palabra crean un vínculo mutuo y se implican en una situación - no totalmente programada - de participación conjunta en una tarea formativa ${ }^{20}$. De ahí podemos concluir que es importante generar una actitud educativa dispuesta a evitar los meros contactos en favor de encuentros auténticos y dispuesta también a crear situaciones y prácticas formativas que faciliten la multiplicación de encuentros personales.

Pero, para que se produzca una relación educativa auténtica, no basta con una sucesión de encuentros. Pese a su importancia, es necesario que el encuentro contenga una clara iniciativa del educador orientada a acoger, reconocer y aceptar al educando $^{21}$. No se trata de encontrarse para escrutar o dominar, sino para demostrar que se le estaba esperando, para manifestar que se tienen esperanzas en sus posibilidades, para cuidar de él y ayudarlo en todo lo posible, para reconocerlo a través de una escucha sin filtros y, finalmente, para aceptarlo tal como se nos muestra. Una abertura al otro que no debe confundirse con una actitud pasiva o dominada por el destino; se trata de mostrar una abertura combativa y dispuesta a entregarse en la ayuda. Algo que va más allá de los contactos teñidos de indiferencia o legalismo. Cuando se logra una relación de acogida y reconocimiento se están poniendo las bases de la entrada en el mundo social. La socialización depende de que alguien esté dispuesto a acoger y reconocer: de que alguien esté dispuesto a vincularse afectivamente.

Llegados a este punto, estamos en el umbral de los dos movimientos morales que se producen en toda relación humana lograda. Nos referimos a la responsabilidad por el otro y al respeto que genera obligación. Con el primer movimiento aludimos a la responsabilidad incondicional del educador hacia el educando ${ }^{22}$. La relación educativa supone una responsabilidad ética del adulto hacia el joven; una responsabilidad que no está limitada por ninguna condición que pueda eximirla. El otro a través de su corporeidad —el rostro-, pero yendo más allá de ella, muestra su contingencia, su necesidad, su debilidad y reclama ayuda sin condiciones y sin ofrecer nada a cambio. En esta exigencia callada del alumno y en el deber de colmarla responsablemente por parte del educador reside el primer movimiento moral que encierra la relación educativa. Pero a la vez, cuando un joven se siente apreciado por un adulto - recibe afecto, cuidado, se comparte tiempo con él, se alaba su esfuerzo y se le valora de modo incondicional-, acaba también por apreciar al adulto. $Y$ cuando se ha creado un vínculo de afecto recíproco, es más fácil que los educadores puedan indicar valores y conductas a los jóvenes con una

\footnotetext{
interacción. Buenos Aires, Tiempo Contemporáneo. Ídem (1961) Encounters: Two Studies in the Sociology of Interaction. Indianápolis, Bobbs-Merrill. Ídem (1979) Relaciones en público. Madrid, Alianza. Blber, M. (1949) ¿Qué es el bombre? México, FCE. Ídem (1974) Yo y tú. Buenos Aires, Nueva Visión.

20. Gijón, M. (2003) Espacios de educación moral en una comunidad escolar. Universitat de Barcelona. Tesis doctoral. Facultat de Pedagogía.

21. DuCH, L1. (1997) La educación y la crisis de la modernidad. Barcelona, Paidós.

22. LEVINAS, E. (1991) Ética e infinito. Madrid, Visor.
} 
mayor probabilidad que los adoptarán debido al afecto que les profesan ${ }^{23}$. Se genera en los jóvenes un sentimiento de obligación en cierto modo paralelo, aunque distinto, a la responsabilidad que antes impulsaba a los educadores en relación a los jóvenes. Estamos ante una doble obligación moral que no puede ser eterna ni explica todos los dinamismos y tareas de la educación moral, pero que resulta del todo imprescindible como uno de sus espacios y momentos.

¿Qué tipo de intereses y de medidas pueden proponerse si consideramos que el primer espacio de formación moral son las relaciones interpersonales? Si la relación educativa auténtica supone encuentros de acogida y reconocimiento que conducirán a sentimientos de responsabilidad y respeto, parece evidente y lógico proponer que se debería seguir ahondando en la consideración de la educación como un encuentro entre adultos y jóvenes ${ }^{24}$, que se debería ser más beligerante en favor de una comprensión de la tarea educativa como parte de una profesión de proximidad y ayuda que exige calidez y reconocimiento del otro para lograr sus objetivos y, por último, que pese a la dificultad natural que presenta el traducir tales consideraciones en propuestas es imprescindible realizar un esfuerzo para concretar medidas precisas ${ }^{25}$. Probablemente, algunas de estas medidas puedan incidir en el refuerzo de la figura y la dedicación del tutor, así como de la generalización de la función tutorial a la mayor parte del profesorado de los centros.

\subsection{El espacio de las tareas curriculares}

El segundo nivel del modelo de formación cívico-moral que estamos desarrollando aborda lo que vamos a llamar "tareas curriculares"; es decir, el conjunto de quehaceres que se llevan a cabo en el seno de un grupo-clase, que tienen una intención manifiesta - aunque quizás no exclusiva- de trabajar sobre valores y que se inscriben en el tiempo destinado a las diferentes materias y ocupaciones que ofrece el currículum. Esas tareas orientadas a la formación cívico-moral pueden quedar distribuidas de modo transversal a lo largo de las materias escolares, como ocurre cuando se abordan ciertos temas moralmente relevantes desde la perspectiva de las diferentes áreas escolares. $\mathrm{O}$, por el contrario, condensar el tiempo destinado a tratar temas de valor en ciertos espacios escolares, como podría ocurrir durante el tiempo destinado a la clase de tutoría o a la reflexión ética, o como también sucede en el espacio temporal que puede ocupar alguna materia de libre elección. En síntesis, este nivel del modelo de formación cívico-moral se refiere a

23. Piaget, J. (1999) De la pedagogía. Barcelona, Paidós. Rawls, J. (1979) Teoria de la justicia. México, FCE.

24. Por ejemplo, en la línea de lo que viene realizando el grupo de valores del ICE de la Universidad Autónoma de Barcelona. Mèlich, J. C.; PALAL, J.; PoCri, C. y Fons, M. (coords.) (2000) La veu de l'altre. Bellaterra, ICE de la UAB.

25. Martín, X.; Puig, J. M.; Padrós, M.; Rubio, L. y Trilla, J. (2003) Tutoria. Madrid, Alianza. 
las tareas de aula destinadas a trabajar valores, aunque su ubicación temporal en el currículum puede ser muy variada.

Las tareas curriculares ponen en juego tres grandes bloques de contenido: las cuestiones personal o socialmente relevantes, las disposiciones que constituyen la inteligencia moral y, por último, algunos elementos básicos de la cultura moral de una sociedad. Estos bloques de contenido marcan asimismo el horizonte de alguna de las finalidades de la formación cívico-moral: aprender a considerar reflexiva y críticamente cuestiones controvertidas de la vida social y personal, desarrollar las diferentes capacidades de la inteligencia moral y predisponer a los alumnos a usarlas rectamente en situaciones de deliberación moral y, finalmente, conocer, apreciar y usar un conjunto de conceptos y elementos esenciales de una cultura moral que pueden ayudar a comprender y valorar ciertos hechos y controversias que se someten a consideración ${ }^{26}$.

Las tareas curriculares destinadas a trabajar valores deben ser en un espacio pensado para hablar de todo aquello que preocupa al grupo. Los alumnos deberían percibir estas sesiones como una oportunidad para tratar temas de interés y para discutir y abordar juntos situaciones que les inquietan. Si la inteligencia nos permite conducir un proceso de adaptación óptimo al medio físico y cultural, la inteligencia moral hace posible que nos adaptemos y a la vez optimicemos nuestra relación con el entorno social. Las distintas capacidades que configuran la inteligencia moral nos ayudan a relacionarnos con los demás, a respetar las normas sociales, a enfrentarnos a las experiencias vitales y, sobre todo, a considerar los conflictos de valor.

Enfrentarse a experiencias moralmente controvertidas y resolver los dilemas morales que plantea la vida cotidiana requiere algo más que el uso correcto de la inteligencia moral. Así, en el intento de buscar soluciones a los conflictos individuales y colectivos, las personas no sólo ponen en juego sus capacidades individuales, sino que también usan guías de valor que les permitan orientar la resolución de los conflictos. La cultura moral es, junto con la inteligencia moral, un instrumento de primer orden que nos permite regular la convivencia y mejorar nuestras formas de vida. La cultura moral está constituida por elementos de distinta naturaleza que cada sociedad en particular, y también la especie humana en su conjunto, ha elaborado a lo largo del tiempo. En la cultura moral cristalizan ideas, modelos, pautas normativas, prácticas, instituciones sociales y otros elementos que sirven de guías de valor para una comunidad. Se trata de recursos y propuestas que las distintas colectividades reconocen como moralmente válidos y eficaces.

Considerar temas relevantes, desarrollar la inteligencia moral y adquirir elementos esenciales de la cultura moral son tres objetivos de la formación moral que se trabajan a la vez en las sesiones de clase. Es posible dar mayor relevancia a

26. PLIG, J. M. (1995) La educación moral en la enseñanza obligatoria. Barcelona, ICE-LB/Horsori. Ídem (1996) La construcción de la personalidad moral. Barcelona, Paidós. 
alguno de ellos, pero resulta del todo inadecuado pretender aislar cualquiera de estos tres momentos. Por otra parte, los espacios escolares destinados a trabajar aspectos relacionados con los valores no pueden convertirse en clases que caigan en la inculcación de valores ni en la mera transmisión de conocimientos. Es casi imposible y del todo indeseable realizar clases de esta naturaleza. Se trata, por el contrario, de convertir las clases en foros de consideración y diálogo o en momentos que dispongan al autoconocimiento y la reflexividad. ¿Qué tipo de intereses rectores de la investigación y medidas concretas podemos proponer para impulsar el espacio de formación moral que hemos denominado "tareas curriculares"? Para hacer más efectivo el espacio curricular destinado a la formación cívico-moral nos parece adecuado fortalecer propuestas ya vigentes e introducir otras nuevas. En primer lugar, sería oportuno reforzar la consideración transversal de la formación en valores: tanto los contenidos de actitudes, valores y normas propios de todas las áreas, como los temas transversales que abordan cuestiones de valor al filo del contenido propio de cada materia son dos modalidades formativas conocidas pero que requieren un nuevo impulso, así como una voluntad de llegar a propuestas accesibles y a una mayor exigencia en su programación e impartición. Quizás convendría no distribuir la responsabilidad hasta el extremo de diluirla, sino optar por planes quizás más limitados pero también más realizables. Por otra parte, se trataría de dar un impulso especial a aquellas materias que más fácilmente permiten la consideración de valores. El papel de ámbitos curriculares como la educación física, la lectura y la literatura, el cine y la televisión, las ciencias sociales y la filosofía, sin excluir a las demás, deberían tener cierto protagonismo.

En segundo lugar, consideramos que el ámbito de los estudios sociales debería orientarse con mayor fuerza en torno a criterios como los siguientes: realizar una aproximación a la vez local y global a los temas, prestar mayor atención a aquellos conocimientos político-sociales imprescindibles para entender la sociedad donde viven (como, por ejemplo, el funcionamiento de la democracia y el Estado de derecho, el sentido de los impuestos, el Estado del bienestar y muchos otros), incrementar la aproximación reflexiva y crítica a los temas considerados e impulsar una consideración de las temáticas que tenga en cuenta las aportaciones y puntos de vista de otras culturas y civilizaciones. Se trataría de dar a los contenidos sociales un tratamiento que los convierta en verdaderas herramientas para la vida como ciudadanos.

En tercer lugar, y tal como ya hemos adelantado al considerar las relaciones interpersonales, pensamos que es necesario reforzar la figura y las tareas de los tutores y tutoras. En concreto, proponemos que tengan una dedicación de siete horas, de las cuales tres se deberían dedicar a trabajo con el grupo-clase en su conjunto -triplicando pues la actual dedicación-, tres para atención individual al alumnado y a sus familias y una última hora de coordinación con el resto de tutores. Un volumen de dedicación como el propuesto permitiría mejorar la atención personalizada y, sobre todo, daría a la clase de tutoría tiempo suficiente para abordar las cuestiones que ahora tan sólo llegan a apuntarse y que es imposible tratar 
con la intensidad suficiente. Se podría emprender de manera sistemática la tarea de trabajar en los tres ámbitos que hemos adelantado anteriormente -aproximación a temas personal y socialmente relevantes, desarrollo de la inteligencia moral y adquisición de elementos básicos de la cultura moral- y para los cuales contamos ya con múltiples propuestas y recursos.

En cuarto lugar, se debería prestar una atención especial a la conceptualización de las experiencias vitales del alumnado y a la presentación de ciertos contenidos esenciales para la reflexión moral. Para hacerlo posible, y en los últimos cursos de la enseñanza obligatoria, se podría destinar un tiempo a la reflexión ética y al conocimiento de sus contenidos fundamentales, como por ejemplo los derechos humanos. Desde el punto de vista de la filosofía se podría realizar perfectamente esta labor.

En quinto lugar, nos parece esencial difundir y profundizar la idea de que las clases de tutoría y todas aquellas que se inscriben bajo el rótulo de atareas curriculares" que trabajan valores no pueden convertirse en clases de mera transmisión de conocimientos y menos de inculcación unilateral de valores. Por el contrario, se trata de hacer que las clases sean foros de deliberación y espacios de autoconocimiento. Y, en consecuencia, dar al educador un papel de impulsor y conductor de las sesiones. Sin embargo, este tratamiento más activo, igualitario y dialogante de las clases donde hay una consideración de temas de valor no supone rebajar la exigencia ni eliminar la evaluación. No podemos decidir, ni queremos, cómo van a pensar nuestros alumnos, pero sí podemos evaluar la calidad de su trabajo y las adquisiciones que han logrado. En síntesis, hemos de dibujar un modo mucho más flexible y abierto de dar las clases de tutoría y de valores, $y$ hemos de perfilar formas respetuosas y exigentes de evaluación del alumnado.

Finalmente, en sexto lugar, para llevar a cabo estas y otras medidas relativas a la formación cívico-moral del alumnado sería necesario impulsar en la formación inicial y permanente del profesorado una dedicación mucho mayor a las cuestiones relacionadas con la educación en valores. Se debería ir hacia un régimen de obligatoriedad de estas temáticas en la formación inicial y hacia el desarrollo de planes de formación y de innovación en centros.

\subsection{El espacio de la cultura escolar}

El tercer nivel del modelo de formación cívico-moral que estamos presentando dirige su mirada a la forma que damos a las instituciones escolares y a cómo esa forma institucional crea un clima o cultura moral. Solemos aceptar que la relación personal entre educadores y alumnos es una fuente de influencia educativa de primera magnitud, tampoco dudamos de que el desarrollo de las tareas curriculares constituyan una experiencia educativa esencial. Sin embargo, no siempre reconocemos que el clima de una institución educativa ejerce una enorme presión formativa sobre sus alumnos. No es exagerado afirmar que las instituciones en cuanto 
tales son profundamente educativas. Las instituciones tienen forma moral y educan moralmente ${ }^{27}$. Si tales afirmaciones son ciertas, se hace necesario pensar con cuidado el diseño de las prácticas pedagógicas que se realizan en los centros educativos, así como la construcción de un sistema de prácticas que los convierta en comunidades democráticas. Es decir, se hace necesario construir una cultura moral de centro que ejerza una potente acción educativa. La cultura moral no puede quedar en manos del azar, sino que debe ser objeto de una preparación consciente y minuciosa.

Llegados a este punto debemos retroceder un poco para ver mejor la naturaleza de un medio educativo y de su cultura moral. La tesis que deseamos defender es que la construcción de la personalidad moral depende en parte del efecto que ejerce el conjunto de la institución educativa. Lo que se afirma es que la totalidad de la institución es una potente fuerza educativa que incide sin cesar en la formación personal del alumnado. Esta afirmación supone varias cuestiones que vamos a repasar de modo breve. En primer lugar, se afirma algo que solemos expresar de un modo metafórico: la atmósfera del centro nos impregna como por ósmosis cuando nos sumergimos en su realidad. Es decir, los valores que expresa la institución educativa nos empapan y se traducen en hábitos y actitudes personales a medida que usamos sus propuestas. En segundo lugar, ese proceso de empaparse en valores y convertirlos en hábitos y actitudes depende de la capacidad de la institución para hacer vivir realmente los valores que propugna. En la medida que el centro proponga actividades cuya normal realización invite a los alumnos a practicar valores, estaremos impulsando un proceso real de implantación de hábitos y actitudes. En tercer lugar, en cualquier centro educativo hacemos vivir valores a nuestros alumnos a través de las prácticas o actividades que les proponemos. Hemos visto cómo las prácticas de deliberación y autoconocimiento invitan con intensidad a realizar valores como, por ejemplo, el reconocimiento del otro o la autenticidad. Pero en un centro se ofrecen otras muchas prácticas educativas que cristalizan valores e invitan a vivirlos a sus alumnos.

Ahora estamos en condiciones de afirmar que las instituciones educativas - en tanto que medios impregnados de una cultura moral- son sistemas de prácticas pensadas expresamente para educar. Veamos, pues, primero qué entendemos por práctica moral y luego veremos qué es un sistema de prácticas. Entenderemos que las prácticas son cursos de acontecimientos ordenados, coherentes y complejos que han sido pensados para educar. Es decir, las prácticas disponen y rutinizan una serie de pasos que deben llevar a cabo conjuntamente los alumnos entre sí y con sus profesores para alcanzar ciertos objetivos previstos con anterioridad.

27. Jackson, P. W.; Boostrom, R. E. y Hansen, D. T. (2003) La vida moral en la escuela. Buenos Aires, Amorrortu editores. Kohlberg, L. (1992) Psicología del desarrollo moral. Bilbao, Desclée. PiAGET, J. y Heller, J. (1968) La autonomía en la escuela. Buenos Aires, Losada. Powers, F. C.; Higgrns, A. y KoHLBERG, L. (1997) La educación moral según Lawrence Koblberg. Barcelona, Gedisa. 
Objetivos como adquirir saberes, debatir temas significativos, ordenar el material o cualquier otra tarea propia de un aula escolar.

Tal como se acaba de afirmar, las prácticas han sido diseñadas para perseguir objetivos educativos, pero su impacto formativo se multiplica en la medida que cada uno de los pasos que se dan para alcanzar los objetivos previstos cristaliza valores. Las buenas prácticas educativas durante su realización expresan valores: se cumple el objetivo previsto - aprender, debatir, ordenar, etc. - y simultáneamente se actualizan valores - aprender cooperativamente, debatir respetuosamente y con razones, ordenar la clase con cuidado y respetando los turnos, etc.- . En consecuencia, las prácticas exigen a los alumnos participantes un aprendizaje progresivo de formas apropiadas de comportarse; es decir, las buenas prácticas enseñan virtudes. Dicho de otro modo, en los centros escolares bien diseñados los alumnos aprenden y se forman al mismo tiempo ${ }^{28}$.

Pero volvamos al principio: una institución es un sistema de prácticas educativas. No se trata de una sola práctica aislada, ni tampoco de una incoherente multiplicidad de propuestas. Una institución es un sistema; es decir, un conjunto interrelacionado y coherente de prácticas que consigue incrementar el efecto educativo precisamente por la sinergia que se establece entre todas las propuestas. Algo que de modo tan magistral logró Freinet en sus aulas y nos sugiere Dewey cuando nos advierte que no se educa de modo directo sino a través del medio. Algo que hoy preferimos expresar con otras palabras: se educa a través del cultivo de prácticas y la construcción de medios.

Ambos conceptos - diseño de prácticas y construcción de medios- apuntan hacia un mismo objetivo: la reconstrucción del mundo de la vida de las escuelas. La creación de un espacio que sea educativo por sí mismo. Es preciso imaginar formas de convivencia escolar, de animación y de trabajo que predispongan a vivir y aprender de acuerdo a ciertos principios y valores. Diseñar prácticas es idear piezas educativas; es decir, idear procesos que persiguen objetivos específicos y simultáneamente expresan valores. Por otra parte, la intervención educativa consiste también en ensamblar esas piezas de modo que al final se construya una imagen de conjunto coherente. La suma de las distintas piezas pensadas para responder a cada una de las necesidades educativas debe producir una imagen de conjunto: debe producir un medio educativo denso, rico y coherente. Los procesos educativos se viven en cada una de las piezas o prácticas y se vive también en el efecto de conjunto que produce el medio. Queda, pues, justificado decir que una de las principales tareas de los educadores es diseñar prácticas y construir medios.

¿Qué tipo de intereses rectores de la investigación y medidas concretas podemos proponer para impulsar el espacio de la cultura moral de una institución educativa? Para hacer plenamente formativo el espacio de la cultura moral pensamos

28. PLIG, J. M. (2000) La tarea de educar relatos sobre el día a día de una escuela. Madrid, Celeste. Pug, J. M. (2003) Prácticas morales. Barcelona, Paidós. 
que merece la pena ahondar, al menos, en una cuestión de base y desarrollar varias propuestas concretas. Por lo que respecta a la cuestión de base, pensamos que es conveniente ver con mayor claridad de qué modo compiten en la actualidad en los centros educativos las fuerzas que tienden a mercantilizarlos y a imponer en ellos la fría lógica del sistema y, por otra parte, las fuerzas que los reconstruyen como comunidades democráticas, donde la lógica del mundo de la vida se hace predominante. De este modo, se detectarán las causas de la anomia, indisciplina e incluso violencia que surge en algunos centros. Asimismo se podría pensar con mayor detalle qué significa en la actualidad convertir nuestros centros educativos en comunidades democráticas de aprendizaje, convivencia y animación. El esfuerzo por revitalizar y dar un nuevo sentido creíble a los centros nos parece una tarea esencial para lograr la mejor formación cívico-moral.

En cuanto a las medidas concretas, nos vamos a centrar en cuatro líneas de intervención que merecen en el futuro una mayor atención y, sobre todo, un mayor esfuerzo por llevar a cabo lo que a menudo tan sólo se proclama. En primer lugar, y como ya hemos apuntado, se trata de esforzarse por convertir los centros en comunidades democráticas de aprendizaje, convivencia y animación. Y, para llevarlo a cabo, se requiere ante todo prestar a esta cuestión la misma atención que prestamos a los contenidos de cada una de las materias que se imparten en el centro. La cultura moral transmite un contenido al menos tan importante y penetrante como el que transmiten las respectivas materias. Por lo tanto, se trata de pensar, planificar y realizar un verdadero programa de cultivo de prácticas y construcción de medio para hacer del centro una comunidad democrática.

Por otra parte, supone también prestar una atención más analítica a cada una de las prácticas educativas que tiene instituidas el centro y a las que debería implantar. Ver si las prácticas de transmisión de conocimientos son adecuadas - se permite el trabajo en grupo, se impulsa la experimentación, se diversifica el saber según las necesidades de los diferentes alumnos, etc.-; comprobar si contamos con suficientes propuestas para impulsar la convivencia - existen mecanismos de resolución de conflictos, se impulsan la tareas de cooperación, se establecen metas atractivas, etc. $-y$, finalmente, detectar si damos la importancia que merecen a las prácticas de animación - se crean talleres de lectura, se organizan actividades festivas, se abre la escuela a las familias, etc.- Diseñar y cultivar con detalle estas u otras prácticas adecuadas a cada realidad es contribuir a crear una cultura moral realmente educativa.

En segundo lugar, la cultura moral de las instituciones educativas debería abrirse de un modo especial a la participación del alumnado. Los alumnos no pueden quedar como sujetos pasivos, sino que se han de convertir en protagonistas de su educación y aquí en protagonistas de la institución educativa. Para ello se han de poner en marcha planes para incrementar la participación del alumnado en diferentes instancias del centro. Desde la participación en el aula a través de las asambleas, hasta la elección de delegados y asunción de responsabilidades concretas, a otros muchos mecanismos y procesos que favorecen su implicación. En todo caso, 
la participación supone la institucionalización de instancias de deliberación y mecanismos de cooperación en la realización de iniciativas previamente acordadas.

En tercer lugar, la participación requiere también la apertura de espacios y posibilidades de servicio a la comunidad escolar y a la misma sociedad. Uno de los mejores dinamismos de formación cívico-moral es la realización de actividades a favor de la comunidad. La sensibilización, la responsabilidad, la destreza, la implicación cívica, la crítica son tan sólo algunas de las posibilidades que abren las actividades de servicio. Entre tales prácticas vamos a destacar la realización de cargos de la clase, muy apropiada para las edades inferiores, y las actividades de aprendizaje y servicio, más apropiadas para los alumnos de mayor edad. Pensamos que es difícil una educación cívico-moral completa si no contempla la posibilidad de llevar a cabo acciones cívicas de servicio, y si a la vez estas acciones no se completan con un verdadero estudio escolar de alguna de las dimensiones de la realidad sobre la que se ha incidido y del tipo de intervención que se ha realizado. Cabe, pues, proponer el impulso de tareas de aprendizaje y servicio, en especial en los centros de secundaria, en colaboración con diferentes instituciones sociales.

En cuarto lugar, y para finalizar este apartado, proponemos la creación de una nueva figura educativa, pensada para los centros de secundaria, que mezclando el perfil del pedagogo y del animador sociocultural se responsabilizara en cada centro de impulsar muchas de las propuestas que hasta aquí hemos previsto y que, además, tal como veremos en el próximo apartado, coordinara la actividad que los centros deberían ofrecer durante las horas no curriculares en colaboración con otras instituciones del entorno. Pero veamos ahora con algo más de detalle lo que deberían ser algunas de sus ocupaciones. Quizás la manera más rápida de describir sus tareas fuese decir que debe impulsar todas las prácticas educativas que trascienden el aula o que se realizan del todo en su exterior; es decir, que son propuestas que implican a todo el centro. También debe cuidarse de impulsar las actividades que hemos calificado como no curriculares. A modo de ejemplos, se trataría de participar en la coordinación de los tutores y la fijación del Plan de Acción Tutorial, en el impulso a algunas de las prácticas de convivencia y animación, en la ayuda a la asociación de alumnos y a la de madres y padres y, finalmente, en la coordinación de las actividades culturales que podrían ofrecer los centros fuera del horario escolar.

\subsection{El espacio comunitario}

Hasta aquí es como si hubiéramos venido considerando a la escuela como una entidad educativa cerrada: la institución educa moralmente por medio de los encuentros interpersonales que en ella se producen, de los contenidos curriculares (específicos o no) que en ella se trafican y de la cultura moral que es capaz de construir y desarrollar en su interior. Éstas son, ciertamente, las vías y los espacios fundamentales a través de los cuales tiene lugar en la escuela la educación moral. 
Pero, si nos quedáramos ahí, correríamos el riesgo de caer en una suerte de planteamiento escolar autárquico que no sería ni real ni deseable. No sería real puesto que la escuela no es, de hecho, un sistema cerrado en relación a ninguna de sus funciones y mucho menos por lo que se refiere a la de la formación moral o en valores. Y tampoco aquella estrategia autárquica sería deseable, ya que la tendencia a aislar la escuela de su entorno, la cual, por otro lado, ha estado muy presente a lo largo de la historia ${ }^{29}$, se ha demostrado ineficaz e incluso contraproducente para la formación de una ciudadanía consciente, responsable, crítica y participativa.

Por tanto, nuestra opción es la de una escuela abierta a su entorno y enraizada en la comunidad más amplia de la que forma parte. Esta opción crea un cuarto espacio para la educación moral en la escuela. Es el espacio que llamamos comunitario y que se desarrolla por medio de dos vías complementarias: la participación de la comunidad en la escuela y la participación de ésta en la comunidad. Seguidamente, nos referiremos por separado a cada una de ellas.

Abrir el centro educativo a la participación de la comunidad puede suponer, a la vez, varias cosas, todas ellas positivas: desde hacer realidad el funcionamiento eficaz de los consejos escolares, hasta conseguir que los equipamientos de los centros puedan ser de uso comunitario fuera de los horarios lectivos, pasando por la optimización de las asociaciones de madres y padres de alumnos o la colaboración voluntaria y desinteresada de otros miembros de la sociedad civil en tareas escolares diversas. Por poner sólo un ejemplo concreto de esto último, piénsese en la proyección moral que puede tener para los escolares la experiencia vital de personas mayores que participan en esas actividades intergeneracionales que organizan algunos centros educativos. Se trata, en definitiva, de aprovechar todas las sinergias que se crean cuando la comunidad se corresponsabiliza de la escuela, y, por lo que respecta específicamente a la educación moral, se trata de multiplicar las fuentes proveedoras de valores en la escuela. Porque una escuela abierta a la participación comunitaria es siempre una escuela axiológicamente mucho más rica y una escuela que expresa mejor la complejidad y la pluralidad social.

La otra vía del espacio comunitario de la educación moral es la participación de la escuela en la comunidad. La experiencia de los alumnos de participar activamente en la vida de la escuela se debe completar con la experiencia de la participación fuera de ella en actividades de relevancia social. En uno y otro caso se trata de superar una educación moral quizás demasiado académica o demasiado basada en una reflexión y discusión faltas de implicación personal y de experiencia directa en aquello que se considera. En tal sentido, entendemos que la educación moral debe partir de la experiencia cotidiana de la vida escolar, pero también deber salir de la escuela para implicar a sus alumnos y alumnas en proyectos de actividad con trascendencia social y cívica. Al entrar en contacto con aspectos de la realidad a veces alejados y poco conocidos, al implicarse en proyectos ć́vicos de

29. TRILIA, J. (2002) La aborrecida escuela. Barcelona, Laertes. 
interés, al llevar a cabo intervenciones socialmente eficaces y humanamente gratificantes se conseguirá un tipo de experiencia de una hondura difícilmente igualable. Por otra parte, la escuela estará preparando a los jóvenes para el compromiso cívico y capacitándolos para actuar con eficacia en su entorno social.

Presentadas estas dos vías inversas pero complementarias del espacio comunitario de la educación moral, conviene introducir un par de precisiones para evitar algún malentendido que pudiera generarse por lo dicho hasta aquí.

La primera precisión es que, cuando hablamos de que la escuela debe abrirse a la comunidad de la que forma parte y arraigarse a ella, ha de sobreentenderse que tal integración comunitaria ha de llevarse a cabo de una forma crítica. La escuela debe ser muy permeable al medio, pero selectivamente permeable. La función intencionalmente educativa de la escuela exige que en su relación con el medio lleve a cabo una tarea de selección, de criba: arraigarse pero críticamente, integrarse y abrirse a según qué sí y a según qué no. La escuela no debe ni puede reflejar y encarnar mimética e indiscriminadamente los valores dominantes de la sociedad a la que pertenece. Ya se sabe que tampoco nunca le será posible (ni sería deseable) desmarcarse totalmente de ellos, pero la autonomía relativa de la que goza le ha de permitir a la escuela la criba y la crítica de la que hablamos. Cuando se dice, a menudo en un tono como pesimista e incluso fatalista, que los valores que intenta cultivar la escuela son neutralizados, cuando no directamente destruidos, por los que los niños viven y reciben fuera de ella (en la televisión, la publicidad, incluso a veces en la familia, a través de determinados modelos sociales, etc., etc.); cuando se advierte que el valor de la cooperación que la escuela pretende privilegiar resulta antagónico con la competitividad desaforada que se vive en el medio; que la publicidad que induce al consumismo más desmedido choca frontalmente con los valores de la austeridad, del consumo responsable o del desarrollo sostenible que se trabajan en la escuela; que la educación para la paz que ella asume se da de bruces con la violencia de todo tipo (real y simbólica) que se ve y se vive en el mundo, con guerras injustas y mentirosas que quienes debieran ejercer de modelos morales incluso justifican; cuando el respeto, la civilidad y el buen gusto son valores con los que la escuela se quiere abanderar y, en cambio, en televisión a las audiencias se les ofrecen sobredosis cotidianas de basura... En definitiva, cuando las contradicciones entre los valores que la escuela quiere cultivar y algunos de los que dominan en el medio social resultan tan flagrantes, hay quienes inmediatamente tiran la toalla pedagógica y renuncian a la educación moral en la escuela. No se dan cuenta de que, precisamente, son estas contradicciones reales las que justifican y hacen aun más necesaria la tarea de educación en valores en la institución escolar. Si la cooperación, el pacifismo, el respeto, la civilidad... fueran ya los valores que primaran y se respiraran en la comunidad y en el medio social, la escuela podría dedicarse tranquilamente a otros menesteres: lo que ya bien se aprende mediante la educación informal no tiene por qué enseñarlo la escuela. Por eso, decíamos que la permeabilidad escuela-comunidad y el arraigo de la primera en la segunda han de ser siempre críticos y selectivos. Es como una 
porosidad que filtra para aprovechar e integrar los mejores valores de la comunidad y que permite devolvérselos incluso mejorados y ampliados.

La segunda precisión que hay que hacer se refiere a la noción de comunidad que estamos manejando. Hasta no hace mucho, el espacio comunitario de la escuela podía dimensionarse en términos locales, territoriales o geográficos: la comunidad de la que formaba parte la escuela era el barrio, el pueblo, la ciudad... Participar en la comunidad significaba implicarse en acciones o proyectos - sociales, culturales, lúdicos...- de la localidad. Eso sigue siendo necesario y conveniente, porque el contexto físico de la experiencia vital de los escolares sigue siendo, en cierto grado, su entorno territorial inmediato. Sin embargo, no hay que decir que los actuales medios de transporte y las tecnologías de la comunicación han ampliado y diversificado extraordinariamente las fuentes de experiencia (real y virtual) al alcance de los niños. Actualmente, este que llamamos espacio comunitario de la educación moral en la escuela puede incluir, tanto la participación de la misma en una fiesta tradicional de la localidad, como la implicación real de una escuela española en un programa solidario con América Latina o en un proyecto de cooperación que a través de Internet vincula a escuelas de diferentes países. Ciertamente, el actual fenómeno de la globalización y las nuevas tecnologías facilitan y casi obligan a pensar pedagógicamente lo comunitario en términos mucho más amplios. Pero también es cierto que, antes de la eclosión de las nuevas tecnologías y de la globalización, ya había experiencias escolares emblemáticas en cuanto al aprovechamiento de la comunidad como espacio de formación moral mediante una dialéctica muy positiva entre lo local y lo universal. Por ejemplo, las pedagogías de Freinet, Freire o la de aquella escuelita de Barbiana, tan modesta y geográficamente aislada en medio de la montaña toscana y que tan bien acogía las necesidades, realidades e intereses genuinos de los hijos de las familias campesinas de los alrededores, y que, a la vez, resultaba ser mucho más cosmopolita, en el mejor sentido de la palabra, que la mayoría de escuelas de cualquier gran ciudad. En aquella escuelita creada por el sacerdote don Lorenzo Milani, por ejemplo, la lectura y comentario del periódico era una actividad central y cotidiana; los intelectuales, artistas, políticos, sindicalistas amigos de don Lorenzo o simplemente interesados en su experiencia pedagógica que frecuentemente visitaban la escuela eran exprimidos por los chicos de Barbiana; algunos de ellos eran enviados durante las vacaciones a seguir formándose y a trabajar al extranjero, con el compromiso de que cada semana mandaran a la escuela dos o tres cartas explicando su experiencia para que también los compañeros que se quedaban en Barbiana pudieran, vicariamente, beneficiarse de ella... ${ }^{30}$. En fin, un riquísimo y cosmopolita espacio comunitario para la formación moral en la más humilde y geográficamente aislada de las escuelas famosas del siglo pasado.

30. Alumnos De BARBIANa (1970) Carta a una maestra. Barcelona, Nova Terra. FallaCi, N. (1997) Vita del prete Lorenzo Milani. Milano, Biblioteca Universali Rizzoli. 


\section{LA ENSEÑANZA DE LA RELIGIÓN}

Desde nuestra transición democrática hasta ahora, una de las cuestiones educativas que han tenido una presencia pública más frecuente y controvertida ha sido la del lugar de la religión en la escuela. Desde hace un cuarto de siglo no hay año que, por una razón u otra, en los medios de comunicación, en los foros políticos y en las propias instituciones escolares, no aparezcan debates relacionados con ello. Cuestiones como la de la presencia de símbolos religiosos en los centros de enseñanza ${ }^{31}$, el tratamiento en escuelas e institutos de determinados temas muy sensibles para determinadas confesiones religiosas (despenalización del aborto, métodos anticonceptivos, homosexualidad...), el caso de los profesores de religión nombrados por la jerarquía eclesiástica pero sufragados con fondos públicos o el tema que directamente nos va a ocupar aquí: el de la enseñanza de la religión en el sistema educativo formal.

El tema resulta ciertamente complejo, pues comprende diversidad de aspectos: jurídicos y políticos (Constitución española, acuerdos del Estado español con el Vaticano, leyes educativas, competencias autonómicas...), históricos (lastres del nacionalcatolicismo franquista, proceso de secularización...), ideológicos (laicismo, confesionalidad...), sociales (realidad cada vez más multicultural y multirreligiosa de nuestra sociedad...), además, claro está, de las dimensiones más directamente pedagógicas de la cuestión (curriculares, organizativas, metodológicas, evaluativas, etc.). Asimismo, la cuestión involucra, con beligerancias diversas y a menudo enfrentadas, a diferentes colectivos y sectores sociales: confesiones religiosas, partidos políticos, asociaciones de padres y madres de alumnos, sindicatos de profesores, patronales de la enseñanza... Esta complejidad imposibilita que aquí podamos desarrollar el tema en toda su extensión y deteniéndonos en los múltiples matices (conceptuales, argumentativos, prácticos...) que constantemente aparecen cuando se trata sobre él. Sin embargo, por lo que seguidamente veremos, no nos parecía que, en un artículo como éste, pudiéramos obviar esta cuestión. En el escaso espacio del que disponemos nos vamos a limitar a presentar y razonar, muy brevemente en dos epígrafes, los aspectos principales que pueden caracterizar nuestra posición al respecto. Antes, sin embargo, nos parece necesario justificar la presencia de este apartado sobre educación religiosa en un artículo sobre educación moral.

No hay duda de que ambas dimensiones educativas se encuentran relacionadas. Lo están, entre otros, por dos motivos. El primero es que, aunque conceptualmente no se pueda ni deba identificar a la educación religiosa con la educación moral, sobre todo bajo determinadas concepciones de la una y de la otra, ambas interseccionan en algunos puntos: la moralidad es una de las dimensiones presentes en muchas

31. El contencioso sobre el particular es, desde hace ya bastantes años, muy notorio en Francia, pero también se ha dado la polémica, suscitada por casos y situaciones diferentes, en Italia, Alemania, EE.UL. y España. 
formas de entender la religiosidad y también hay concepciones morales directa y explícitamente fundadas en creencias religiosas. El segundo motivo de la relación entre la educación moral y la educación religiosa es que, con razón o sin ella, se las ha vinculado curricularmente en el sistema educativo español: durante el franquismo, porque una religión (la católica) se impuso como fuente y guía principal de moralidad y porque en el sistema educativo la confusión entre educación moral y religiosa era total; en el periodo democrático, porque en algún momento el lugar curricular de la educación moral se ha hecho depender de la religiosa (asignaturas alternativas). En este sentido, pensamos que, a pesar de las relaciones conceptuales y de las intersecciones de contenido que realmente puedan existir entre ambas, para enfocar hoy correctamente el tema en el marco del sistema educativo formal es metodológicamente necesario distinguir claramente entre ellas y evitar que el lugar asignado a la una sea subsidiario del lugar que se asigne a la otra. Ni la educación moral puede ofrecerse como la alternativa laica a la educación religiosa, ni esta última puede fagocitar a la educación moral. Vincularlas de tal forma -como se ha hecho a veces - genera confusión, las desnaturaliza a las dos y, por tanto, desvía la solución efectiva del problema. Precisamente, esta confusión o subsidiariedad con que se ha planteado la cuestión educación moral/educación religiosa es lo que nos ha obligado a incorporar estas reflexiones sobre la segunda en este trabajo cuyo objeto propio es la primera.

\subsection{Cultura religiosa}

Otra de las formas de confundir la discusión consiste en no distinguir claramente entre la educación dirigida a transmitir y a estimular la reflexión sobre lo que se ha dado en llamar "cultura religiosa" y la orientada a formar en una fe o en unas creencias religiosas determinadas. Aquí nos referiremos a lo primero y en el epígrafe siguiente trataremos de lo segundo.

Pensamos que es muy poco discutible que el sistema educativo deba proponerse garantizar que todos los alumnos adquieran el conocimiento suficiente sobre el hecho religioso. La religión es un fenómeno antropológico, sociológico, cultural e histórico relevante $y$, por tanto, el currículum escolar tiene que incorporar los contenidos pertinentes en relación a ello. Ya es un tópico afirmar que no es posible comprender muchos aspectos de la historia del arte y de la cultura, así como una porción muy considerable de la realidad social y de los acontecimientos políticos del pasado sin conocer el papel que en todo ello, y para lo bueno y lo malo, tuvieron las religiones. Y por el hecho de que la religiosidad es también un fenómeno actual, comprender la propia coetaneidad supone acercarse cognitiva y valorativamente al hecho religioso. Creemos que todo eso es aceptado prácticamente por todos - al menos por cualquier persona mínimamente culta y razonable, con independencia de las creencias religiosas que se tengan o no se tengan-. Del mismo modo que no es necesario ser monárquico para comprender el papel 
histórico jugado por las monarquías, tampoco es necesario ser, pongamos por caso, católico, para entender la relevancia que ha tenido el catolicismo en Europa y en el mundo entero durante veinte siglos. Por tanto, la polémica de fondo no radica en si la cultura religiosa debe o no estar presente en el currículum escolar; la discusión de fondo está en el lugar escolar de la educación dirigida a transmitir una fe o creencia religiosa determinada.

Eso no obstante, sí que es cierto que también existen problemas relacionados con la transmisión escolar de la cultura religiosa. Lo que ocurre es que estos problemas —seguidamente mencionaremos algunos de ellos- son más fácilmente afrontables y resolubles cuando se separan adecuadamente de los que se refieren a la educación en una fe determinada. Se reduce en ellos (aunque no se elimine del todo) el lastre ideológico y político de la polémica y se convierten entonces en cuestiones pedagógicas mucho más técnicas. Por ejemplo, la de la ubicación de la cultura religiosa en el currículum: aceptada su presencia, habrá que determinar su volumen y si se imparte de forma transversal (distribuida en las materias pertinentes) o específica (asignatura de cultura religiosa). Incluso podría plantearse la idoneidad de una fórmula mixta consistente en distribuir tranversalmente contenidos de cultura religiosa y, a la vez, en algún curso introducir una materia específica sobre la misma. En cualquier caso, se trataría de una cuestión curricular pareja a la que se plantea respecto a cualquier otro tipo de contenido curricular (científico, lingüístico, humanístico, artístico, moral, de educación física, etc.). La determinación de la cantidad de tiempo lectivo que se le destine a la cultura religiosa habrá de establecerse ponderando la importancia relativa que, de acuerdo con las finalidades estipuladas para el sistema educativo formal, se asigne a cada tipo de contenido. Creemos que la fórmula vigente a partir de la aprobación de la nueva ley (LOCE) y que establece una nueva área específica con dos opciones (la confesional y la no confesional) presente en todos los cursos resulta excesiva y obedece, en realidad, a la voluntad de convertir a la opción confesional (lo que nosotros describíamos como educación en una fe o creencia determinada) en una materia escolar curricularmente igual a las demás. Es decir, que ocurre algo parecido a lo que ocurría antes con la confusión entre educación religiosa y educación moral: de hecho se está aquí subalternizando a la cultura religiosa para justificar la presencia evaluable y en horario lectivo de una concreta educación religiosa confesional.

Otro de los problemas pedagógicos que plantea la cultura religiosa como contenido escolar es la neutralidad, imparcialidad y objetividad a las que habría que tender para su impartición. Es obvio que ante contenidos tan ideológicamente marcados y respecto a los cuales las proyecciones personales de los profesores pueden estar tan presentes, garantizar tales condiciones no resulta fácil. Pero, en cualquier caso, este problema relativo a la impartición no confesional de la cultura religiosa tampoco sería sustancialmente distinto al de la impartición del conocimiento histórico, social, filosófico o incluso estético, y, en general, de cualquier materia escolar con contenidos diversamente interpretables o que planteen cuestiones 
socialmente controvertidas ${ }^{32}$. Así, las condiciones que habría que poner para la impartición no confesional de la cultura religiosa serían semejantes a las que se aceptan para otras materias. Por ejemplo, a un profesor de filosofía, aunque sea platónico, habrá que exigirle que no minimice ni distorsione la aportación de Aristóteles, o a un apasionado de la pintura abstracta que no descalifique a los pintores figurativos. De hecho, aceptando el presupuesto de que la impartición de la cultura religiosa no ha de suponer la intención (explícita o enmascarada) de hacer proselitismo o adoctrinar en un sentido u otro, al profesorado encargado de la misma no se le plantean, en relación a ello, ni más ni menos problemas que a los de otras materias "interpretables". Si acaso, quizás en este momento exista al respecto un plus de dificultad para el caso de la cultura religiosa por el peso de una tradición escolar en que, a menudo, el conocimiento del hecho religioso era inseparable del puro y simple adoctrinamiento.

\subsection{Educación religiosa confesional}

No obstante lo anterior y como ya avanzábamos, el problema de fondo no está en la impartición curricular de la cultura religiosa, sino en el lugar de la educación religiosa confesional en el sistema educativo formal. Es decir, en la utilización del marco institucional de la escuela (instituto, etc.) para la formación en una fe o creencia religiosa determinada. Nuestra posición al respecto es que, en un Estado aconfesional, la formación en una determinada creencia religiosa no puede ser tarea del currículum escolar. Corresponde a las familias, a las iglesias o a las asociaciones privadas que así se lo propongan el propagar, educar y vivenciar la fe en la que comulguen. En una sociedad plural como la nuestra (en realidad, cultural y religiosamente cada vez más plural) y democrática (es decir, que, entre otras cosas, debe aceptar que todos los ciudadanos puedan vivir, cultivar y, si lo desean, propagar legítimamente sus creencias religiosas en igualdad de condiciones) la presencia lectiva de la educación religiosa confesional lleva irremisiblemente o a una incoherencia política flagrante o a una casi imposibilidad organizativa, además de a un planteamiento pedagógicamente indeseable.

Obviamente, sería del todo antÍdemocrático que políticamente se impusiera la presencia curricular unilateral de una confesión religiosa. Si la educación religiosa confesional ha de formar parte del currículum, impartirse en horario lectivo y además sufragarse con dinero público, obviamente esta posibilidad debe estar abierta a todas las confesiones religiosas. Dicho de otra manera, que cada centro de enseñanza debería ofertar tantas clases confesionales de religión distintas como demanda hubiera de ellas en función de las creencias de los alumnos y/o de sus padres. O sea que, en la situación crecientemente multirreligiosa de nuestras

32. Sobre ello y sobre posibles criterios de actuación, TrILLA, J. (1992) El profesor y los valores controvertidos. Neutralidad y beligerancia en la educación. Barcelona, Paidós. 
ciudades no sería raro que cada escuela para cada nivel tuviera que establecer siete, ocho o más clases paralelas de religión para las respectivas confesiones presentes. (Aunque sea entre paréntesis, para ser consecuentes y equitativos con las diferentes creencias y, por tanto, también descreencias, hay que decir que la oferta específica para católicos, protestantes, judíos, musulmanes, budistas... debería completarse con clases especiales sobre religión impartidas desde las perspectivas atea y agnóstica, que no serían lo mismo que la perspectiva aconfesional de la "cultura religiosa"). El hecho de que algunas de las opciones confesionales pudieran ser en un centro o curso determinado muy minoritarias (o incluso individuales), no es razón para que quedaran excluidas: aunque en una clase sólo hubiera un alumno practicante de la religión X, éste tendría exactamente el mismo derecho a tener su espacio lectivo para cultivar su fe que cada uno de los, supongamos, veinte alumnos de la misma clase practicantes de la religión Y. Ya se ve que este sistema, que garantizaría la igualdad de oportunidades para recibir educación religiosa confesional a todos los alumnos, conllevaría considerables problemas de carácter económico y logístico. Pero aparte de estos inconvenientes, sería discutible que tal sistema fuera, desde una perspectiva estrictamente pedagógica, el más idóneo: es de dudoso gusto educativo la imagen de los alumnos de un grupo-clase que juntos aprenden matemáticas, lengua y ciencias sociales, que a la vez dibujan y hacen gimnasia, que juegan juntos en el recreo... y que, luego o entre medias, se separan porque 12 van a clase de catolicismo, 6 a la de religión musulmana, 2 a la judaica, 3 a la protestante y 6 más, hijos de descreídos, a "cultura religiosa".

Por otro lado, algo chirría cuando se pretende convertir a la educación religiosa en sentido confesional en una asignatura como las demás. La cultura religiosa de la que hablábamos antes, es decir, como conocimiento y reflexión sobre el hecho religioso puede ser contenido curricular como cualquier otro, pero ¿cómo se didactiza y evalúa la vivencia de la fe, el sentido de la trascendencia o la aceptación de unas creencias?

Por todo lo anterior, pensamos que el marco curricular y lectivo del sistema educativo formal no es buen lugar para la educación religiosa confesional. De todos modos, si en un apartado anterior defendíamos el espacio comunitario de la escuela como fuente de educación moral, ahora debemos decir que este espacio, que facilita formatos educativos muy diferentes a los convencionalmente lectivos, también puede ofrecer condiciones idóneas para aquella educación religiosa. Nada impide que las escuelas puedan acoger dentro de este espacio comunitario que decíamos, fuera del horario lectivo, actividades, momentos y recursos para una formación religiosa orientada hacia las diversas confesiones presentes en la comunidad escolar. Actividades institucionalmente acogidas por el Consejo Escolar y coherentemente integradas en un proyecto educativo global del centro y contando con la participación de las asociaciones de padres y madres de alumnos, así como de las diferentes Iglesias o asociaciones religiosas del territorio que quieran colaborar con la escuela. 
Podríamos resumir muy sucintamente la posición defendida y razonada hasta aquí sobre la educación religiosa en la escuela mediante los tres enunciados siguientes:

- Conocimiento y reflexión sobre el hecho religioso como contenido curricular para todos los alumnos, impartidos y facilitados desde una intención de neutralidad, imparcialidad y objetividad, y en el respeto hacia todas las concepciones religiosas que aceptan un marco de convivencia democrática y de reconocimiento de los derechos humanos.

- Desvinculación de la educación religiosa confesional del currículum de la escolaridad formal y, por tanto, también del tiempo lectivo.

- Apertura del espacio comunitario de la escuela para que, de acuerdo con el marco general del Proyecto Educativo del Centro, puedan desarrollarse actividades de educación religiosa orientadas según las diferentes confesiones presentes en él.

Somos conscientes de que en algún punto esta propuesta puede friccionar con determinados elementos del contexto legislativo español ${ }^{33}$. Pero es que creemos que tales elementos, por el hecho de ser dudosamente coherentes con una sociedad pluralista y democrática, dificultan más que orientan una solución razonable y justa al pertinaz contencioso español de la educación religiosa en la escuela. Creemos que la forma propuesta - que por supuesto habría que perfilar mucho másestá en la línea de que la escuela pueda contribuir a la construcción de unos conocimientos y valores que habrían de ser compartidos por toda la ciudadanía, y que, a la vez, partiendo del respeto hacia las diferentes opciones religiosas, pueda facilitar incluso la profundización en ellas.

\section{LA FORMACIÓN DEL PROFESORADO EN EDUCACIÓN MORAL}

\subsection{La necesidad de una formación para la educación moral}

La práctica pedagógica y la educación no cambian porque así lo establezcan las disposiciones legales que regulan el sistema educativo o las orientaciones curriculares que establecen los aprendizajes necesarios en cada ámbito. Ni siquiera la existencia de materiales que faciliten tales aprendizajes es suficiente para generar tales cambios. La manera como el profesorado aborda su tarea y el pensamiento de aquél en relación con la conveniencia o no de determinados cambios son factores decisivos. El mejor diseño legal, la mejor orientación curricular y el mejor material pueden ser echados a perder en manos de un profesorado no convencido o que no se sienta cómplice del objetivo que se persigue. Y también, en no pocas

33. Concretamente con los Acuerdos entre el Estado español y el Vaticano firmados durante nuestra transición democrática. Y, a partir de ahí, también con ciertos desarrollos legislativos y normativos que pretenden dar forma a tales acuerdos. 
ocasiones, el buen hacer de maestros y maestras ha logrado objetivos de aprendizaje y educativos de manera excelente sin apenas marco legal, orientación ni material adecuado.

En el caso de la educación moral, de la atención pedagógica al desarrollo moral y de la educación en valores, lo afirmado hasta aquí no sólo es cierto sino que además adquiere un significado especial. A nuestro modo de entender la tarea de educar en valores morales requiere una forma de pensar y de hacer en educación que no siempre está presente en toda persona interesada en dedicarse al ejercicio del profesorado ${ }^{34}$. Ésta es una de las razones por las que proponemos la necesidad de una formación inicial y permanente del profesorado y de los educadores en general adecuada a su función ética y pedagógica-moral.

Con intención de ordenar lo mejor posible el tratamiento de la educación moral en la escuela hemos analizado con anterioridad cuatro espacios, el de las relaciones interpersonales, el de las tareas curriculares, el de la cultura escolar y el del espacio comunitario. En los cuatro se producen situaciones de aprendizaje ético y en los cuatro la acción del profesorado y de los educadores es decisiva.

Los aprendizajes éticos se construyen como mínimo a través de tres vías ${ }^{35}$. Éstas son, la práctica y el ejercicio, la observación y la elaboración y construcción personal. A través de ellas, y sobre todo de la tercera, la persona que aprende interactúa con sus contextos de vida, recibiendo la influencia de las prácticas y modelos que conforman tales contextos, a la vez que regulando y controlando los mismos en función de procesos de maduración personales y en especial de desarrollo cognitivo. La acción del profesorado y de los educadores incide en las tres vías.

En la primera porque su forma de abordar la tarea genera unas prácticas y propicia un espacio muy potente de aprendizaje ético en el alumnado a través del ejercicio y del aprendizaje de hábitos. En la segunda porque su función y la consideración que de la misma se tiene hacen que su forma de pensar y de comprender la realidad así como su manera de actuar se conviertan en modelos susceptibles de ser objetos de aprendizaje social a través de la imitación y, por lo tanto, en factores de marcaje social en el alumnado. En la tercera vía porque su especial preparación en el manejo de recursos y el dominio de estrategias para optimizar competencias morales de la persona como el diálogo, la empatía o el juicio moral entre otras, será decisiva para el logro o no de los objetivos de educación moral que nos propongamos. En los tres casos, por las prácticas que genera en la forma de entender la vida cotidiana de la escuela, por el modelo que muestra en la forma de actuar y de comprender el mundo y por el nivel de competencia profesional en su desempeño como educador moral, la formación es necesaria.

34. HANSEN, D. (2002) Explorando el corazón moral de la enseñanza. Barcelona, Idea-Universitaria.

35. Martínez, M.; Buxarrais, M. R. y Esteban, F. (2002) La universidad como espacio de aprendizaje ético, Revista Iberoamericana de Educación, 29, 17-43. 
Tal formación debe integrar elementos conceptuales y procedimentales relacionados con la educación moral y en especial aprendizajes de actitudes y valores que promuevan el trabajo cooperativo entre el profesorado y con el resto de profesionales que inciden en los espacios señalados. Es necesario entrenar al profesorado a trabajar en equipo porque su tarea no puede desarrollarse de forma satisfactoria si la aborda sólo a título individual; a pactar mínimos en la forma de tratar las cuestiones social y moralmente controvertidas y también a participar en la elaboración de contratos morales y proyectos educativos de centro y de comunidad. Sin embargo, conviene que prestemos atención no sólo a los planes de formación del profesorado. Conviene fijar la atención en los planes de formación que preparan, o en un futuro deberían preparar, para ejercer otras funciones pedagógicas: educación social; pedagogía sociocultural, como señalábamos en el apartado anterior al referirnos a un nuevo profesional de la educación que centra su función en el espacio de la cultura escolar y en el espacio comunitario; dirección de instituciones educativas, entendiendo éstas como aquellas que comparten con la comunidad próxima la tarea educativa escolar y comunitaria; y de forma especial la función de tutoría. El ejercicio de estas funciones y especialmente la tutoría son funciones de especial contenido y densidad pedagógica y moral.

Ciertamente todo profesor o profesora interviene en la formación moral del educando en la medida en que forma parte del espacio de relaciones interpersonales del modelo de educación moral que estamos proponiendo y, por lo tanto, participa en encuentros y establece vínculos. De igual forma el profesorado selecciona materiales curriculares, libros de texto, temas relevantes; organiza el trabajo escolar y la convivencia en el espacio del aula y establece normas, genera, o no, participación y debate en torno a cuestiones controvertidas ${ }^{36}$ y ofrece, o no, pautas y elementos de la cultura moral a escala local y global. Pero el tutor o la tutora, además, juega un papel esencial tanto por el posible carácter transversal en el modo de tratar las tareas curriculares como por el posible carácter específico, tutoría o asignatura, a través del que éstas puedan desarrollarse y además por la tarea de coordinación que ejerce, o que debería poder ejercer en buenas condiciones, en relación con el resto del profesorado y por su relación con las familias. De igual manera su función es clave en el tercer espacio, el de la cultura escolar, sobre todo si entendemos que ésta incorpora una dimensión comunitaria orientada a la construcción de ciudadanía activa y que debe entenderse en el marco de un contexto que va más allá de lo escolar en sentido estricto. De igual forma y en concreto en el espacio de cultura escolar y en el comunitario, el buen desempeño de funciones pedagógicas como las señaladas en relación con la animación sociocultural y comunitaria o la dirección es un factor de calidad clave en nuestra propuesta y consecuentemente reclama acciones formativas específicas, algunas no existentes en la actualidad ni en la oferta de formación inicial ni de formación permanente.

36. TriLlA, J. (1992) El profesor y los valores controvertidos. Barcelona, Paidós. 


\subsection{Sobre los contenidos de aprendizaje y el modelo de formación}

Es difícil, desde un punto de vista conceptual, separar la formación inicial de la permanente de cualquier profesional en general y del de la educación en particular. Sin embargo, en la práctica y por razones obvias, sí es posible establecer pautas y modelos de formación diferentes en función de si se trata de la formación en el momento de estudio, formación inicial, o de la formación en el momento de trabajo. La noción de formación continua y de aprendizaje a lo largo de toda la vida no debe entenderse sistemáticamente como sinónimo de un único modelo y estilo de formación. Algunas de las necesidades formativas pueden abordarse mejor en la formación inicial y otras claramente en la formación permanente, es decir, en el puesto de trabajo o después de tener una cierta experiencia. En todo caso el propio modelo de formación en el que aprenden los futuros profesionales o los profesionales en ejercicio debe reunir las condiciones que proponemos, en los diferentes espacios de educación moral considerados, para que como tal modelo de formación sea un buen lugar de aprendizaje ético. Lo que probablemente nos obliga a plantearnos una renovación pedagógica en la universidad y específicamente en los centros responsables de la formación inicial y permanente de los profesionales de la educación.

En ocasiones se opina que la formación del profesorado en los temas que nos ocupan debe serlo, sobre todo, en técnicas y recursos. Es cierto que este tipo de formación es importante y quizás no se le ha prestado suficiente atención o se ha pensado que era fácil de adquirir, incluso a través de la práctica o mediante procesos de ensayo-error. Sin embargo, en esta ocasión queremos referirnos no sólo a este tipo de formación ${ }^{37}$. Nos queremos referir también y en especial a la formación del profesorado en tanto que educador en cuestiones éticas, gestor de convivencia, orientador de padres y madres de familia en temas relacionados con el desarrollo moral y la educación en valores y como tutor. Reconocemos la importancia y necesidad de cursos de carácter metodológico, sobre estrategias y recursos en educación en valores y sobre evaluación en educación moral ${ }^{38}$. Pero, a pesar de la conveniencia de este tipo de acciones, las propuestas de formación, en especial las de formación permanente, deben afectar de forma prioritaria al equipo de profesorado, a las formas de gestión y organización institucionales, al clima moral de la escuela y a la elaboración de un contrato moral entre el profesorado ${ }^{39}$, contrato que debe comprometer en el logro de unos valores como ideales, en el rechazo activo de los contravalores asociados y en la defensa de unas condiciones en la escuela que garanticen

37. VAN MANEX, M. (1998) El tacto en la enseñanza. El significado de la sensibilidad pedagógica. Barcelona, Paidós.

38. BLXARRAIS, M. R. (1997) La formación del profesorado en educación en valores. Propuestas $y$ materiales. Bilbao, Desclée.

39. Martínez, M. (1998) El contrato moral del profesorado. Bilbao, Desclée. 
la posibilidad de una construcción racional y autónoma de la personalidad moral de cada uno y de todos los que crecen y aprenden en ella.

La realidad es que, salvo notables excepciones, este tipo de formación no está presente de forma habitual, ni por supuesto de forma necesaria, en los planes de estudios de las facultades encargadas de la formación del profesorado o de los profesionales de la educación en general, ni por supuesto en los nunca logrados planes de formación del profesorado de educación secundaria. La realidad es más satisfactoria si nos fijamos en los planes de formación permanente y de actualización del profesorado. Pero en todo caso queda mucho por hacer y sobre todo quedan muchos por convencer. Es sorprendente cómo a lo largo de las dos últimas décadas en las que la educación esta enfrentándose a retos real y cualitativamente nuevos, el conservadurismo y gremialismo presente en la mayoría de debates sobre reforma o revisión de planes de estudio de formación del profesorado sigue ejerciendo el efecto nefasto que ejerce en la escasa o nula preparación del mismo en temas como el que tratamos.

En el caso de la formación permanente (en parte menos sujetada por la propia dinámica interna de la universidad y sobre todo necesariamente más abierta a las necesidades que plantea la propia realidad educativa) las propuestas de formación en centros, los planes de zona y los asesoramientos a equipos de profesorado interesados en integrar acciones de educación moral en el proyecto educativo y la vida cotidiana de la escuela son modelos de formación eficaces.

Nuestra propuesta va dirigida a la formación del profesorado no en tanto que especialista en temas morales o éticos, sino en tanto que profesional que, con independencia de su especialidad disciplinar, educa en valores y ejerce o puede ejercer funciones de tutoría. Tal y como hemos afirmado en párrafos anteriores, una de las tareas principales del profesorado y de los educadores en general es diseñar prácticas y construir medios, crear condiciones para una nueva escuela que hagan de ella un espacio no sólo de aprendizajes de diferentes tipos de conocimientos, sino también y especialmente un espacio de aprendizaje ético, de convivencia y de ciudadanía activa. Consecuentemente, y en primer lugar, proponemos que los planes de formación del profesorado y de educadores en general incorporen los elementos formativos necesarios que les permita estar en condiciones de abordar su tarea en los diferentes espacios de educación moral que conforman la escuela y que hemos considerado. En segundo lugar, que les permita valorar la escuela en tanto que espacio generador de un clima o cultura moral como una institución en relación con la comunidad. $Y$, en tercer lugar, que les forme en aquellas habilidades y conocimientos que les permita abordar el trabajo escolar, la convivencia ${ }^{40}$ y la implicación en proyectos que van más allá de lo escolar y que afectan a la comunidad.

40. MARTínez, M. y TEY, A. (coords.) (2003) La convivencia en los centros de secundaria. Estrategias para abordar el conflicto. Bilbao, Desclée.

(C) Ediciones Universidad de Salamanca

Teor. educ. 15,2003 , pp. 57-94 


\subsection{Consideraciones finales sobre la formación del profesorado en educación moral}

En función de nuestra propuesta sobre la educación moral y la función que la escuela ${ }^{41}$ puede ejercer al respecto, formulamos a continuación las siguientes consideraciones finales sobre la formación del profesorado ${ }^{42}$.

1. La práctica debe ser el centro de la formación continua e inicial del profesorado. El objetivo fundamental de la formación es la construcción y consolidación de esquemas de decisión ante las necesidades reales que plantea la práctica profesional. La formación debe entenderse no sólo para compensar deficiencias, ni para estar al día ante nuevos retos y enfoques como por ejemplo pueden ser los relacionados con la educación moral; la formación debe entenderse como una constante que forma parte del desarrollo profesional del profesorado y de manera especial en el ámbito que estamos tratando.

2. Desde los primeros niveles de la educación y sobre todo en los estudios universitarios la biografía del profesor o profesora, en tanto que estudiante, genera con fuerza e insistencia concepciones ingenuas en relación con lo que son o no buenas prácticas en relación por ejemplo con la educación moral que influirán en su desarrollo profesional y que serán aprendizajes resistentes al cambio y difíciles de corregir.

3. La tarea del profesorado no consiste sólo en transmitir conocimientos sino en comunicar conocimiento y un tipo de relación con el conocimiento. La formación inicial o continua recibida por el profesorado también comunica determinados tipos de relación con el conocimiento que influirán en su práctica como docente y de manera especial en los aspectos éticos y morales de su tarea como docente y educador.

4. La combinación equilibrada y simultánea de formación teórica con formación práctica es una condición necesaria para que un modelo de formación sea eficaz. Sin embargo, no conviene identificar el espacio de formación teórica con las instituciones formadoras y el espacio de aplicación, formación práctica, con las instituciones en las que se ejerce la actividad docente. El clima organizacional y la cultura docente de estas últimas influyen y conforman los procesos de aprendizaje y formación tanto teóricos como prácticos incluso con mayor fuerza que el de las instituciones

41. MARTínez, M. y Bujons, C. (coords.) (2001) Un lugar llamado escuela en la sociedad de la información y la diversidad. Barcelona, Ariel.

42. Nuestra posición comparte las formulaciones expresadas en el documento de trabajo de la XIII Conferencia Iberoamericana de Educación celebrada en Tarija, Bolivia, los días 4 y 5 de septiembre de 2003 sobre Renovación de ideas y Formulación de Estrategias Tendentes al Fortalecimiento de Políticas de Formación Docente y que puede consultarse en http://www.oei.es/xiiicie_doc03.htm. 
formadoras. El modelo que proponemos procura que las propuestas de formación se elaboren o procedan de demandas derivadas de las necesidades de la práctica profesional y que la formación que así se adquiera sea significativa en la propia práctica.

5. Con frecuencia las propuestas de formación del profesorado en general están orientadas a la mejora de los procesos de enseñanza y aprendizaje así como los de evaluación. Es necesario intensificar las propuestas orientadas a reformular la cultura moral de la escuela, a la elaboración por parte de equipos de profesorado de proyectos educativos de centro que integren propuestas de educación moral en la línea que planteamos, a la formación para el ejercicio de la tutoría y a la consolidación de estilos docentes justos y democráticos.

6. En este sentido y en el marco del proceso de convergencia europea y de construcción del Espacio Europeo de Educación Superior en el que estamos comprometidos, la formación del profesorado para el ejercicio de la tutoría en todos los niveles educativos debería incorporar las cuestiones consideradas en este artículo y tener la consideración de postgrado. De igual forma debería abordarse la formación en pedagogía sociocultural y comunitaria y en dirección de instituciones educativas, es decir, como postgrado, al que se pudiera acceder no sólo desde la titulación de grado de magisterio o profesorado sino también desde el de educación social y pedagogía.

Ciertamente, la tarea del profesorado adquiere más la forma de una tarea procedimental, de gestión del conocimiento y promoción ética que la de una tarea instructiva en sentido estricto. Sin embargo, no conviene confundirnos. Una cosa es que los objetivos terminales de nuestra función sean más procedimentales, actitudinales y éticos y otra muy distinta que éstos puedan alcanzarse con modelos y propuestas formativas que no contemplen el trabajo sistemático y constante sobre contenidos de aprendizaje de carácter informativo y conceptual.

La tarea de educar consiste en crear condiciones que promuevan en el que aprende, sujeto en situación de interacción social, aquellas capacidades que le permitan gestionar la complejidad, la del conocimiento y la de la vida, la de ahora y la del futuro. Y como la persona es capaz de gestionar la complejidad hasta límites impensables, no es posible que el experto en formación actúe en clave de simplicidad o que no sepa gestionar lo complejo porque, de ser así, difícilmente promoverá algo diferente de aquello que practica. De ahí que nuestra propuesta no pueda limitarse sólo a la introducción de tal o cual materia sobre técnicas y recursos en educación en valores o sobre desarrollo y educación moral en el plan de estudios. Tal y como ya hemos afirmado, a pesar de la conveniencia y necesidad de las mismas, conviene repensar el modelo de formación inicial del profesorado y también, por supuesto, el de formación permanente. En definitiva, conviene 
intensificar la formación ética, la relativa a las teorías del aprendizaje y desarrollo moral, a las buenas prácticas de educación en valores, a las formas de organizar socialmente la convivencia y el aprendizaje en grupo y a la formación en el ejercicio de la tutoría y de los nuevos profesionales de la educación. Conviene un profesorado con densidad informativa y conceptual en cuestiones socialmente controvertidas especialmente de carácter científico, tecnológico, económico, político y sociocultural, y a la vez entrenado en aquellas competencias que le permitan ejercer su tarea pedagógico moral de forma eficaz en la práctica. 